\title{
Unfavorable effect of calcitriol and its low-calcemic analogs on metastasis of 4T1 mouse mammary gland cancer
}

\author{
ARTUR ANISIEWICZ ${ }^{1}$, AGATA PAWLIK ${ }^{1}$, BEATA FILIP-PSURSKA ${ }^{1}$, ELIZA TURLEJ ${ }^{1}$, STANISŁAW DZIMIRA ${ }^{2}$, \\ MAGDALENA MILCZAREK ${ }^{1}$, KATARZYNA GDESZ ${ }^{1}$, DIANA PAPIERNIK ${ }^{1}$, JOANNA JAROSZ ${ }^{1}$, \\ DAGMARA KŁOPOTOWSKA ${ }^{1}$, ANDRZEJ KUTNER ${ }^{3}$, ANDRZEJ MAZUR $^{4}$ and JOANNA WIETRZYK ${ }^{1}$ \\ ${ }^{1}$ Department of Experimental Oncology, Hirszfeld Institute of Immunology and Experimental Therapy, \\ Polish Academy of Sciences, 53-114 Wroclaw; ${ }^{2}$ Faculty of Veterinary Medicine, \\ Wroclaw University of Environmental and Life Sciences, 50-375 Wroclaw; \\ ${ }^{3}$ Department of Pharmacology, Pharmaceutical Research Institute, 01-793 Warsaw, Poland; \\ ${ }^{4}$ Université Clermont Auvergne, INRA, UNH, F-63000 Clermont-Ferrand, France
}

Received June 23, 2017; Accepted October 12, 2017

DOI: $10.3892 /$ ijo.2017.4185

\begin{abstract}
Low vitamin D status is considered as a risk factor for breast cancer and has prognostic significance. Furthermore, vitamin D deficiency increases after adjuvant cancer therapy, which alters bone metabolism increasing the risk of osteoporosis. It is now postulated that vitamin D supplementation in breast cancer treatment delays the recurrence of cancer thereby extending survival. We evaluated the impact of calcitriol and its low-calcemic analogs, PRI-2191 and PRI-2205, on the tumor growth, angiogenesis, and metastasis of 4T1 mouse mammary gland cancer. Gene expression analysis related to cancer invasion/metastasis, real-time PCR, ELISA, western blotting, and histochemical studies were performed. In vitro studies were conducted to compare the effects of calcitriol and its analogs on 4T1 and 67NR cell proliferation and expression of selected proteins. Calcitriol and its analogs increased lung metastasis without influencing the growth of primary tumor. The levels of plasma $17 \beta$-estradiol and transforming growth factor $\beta$ (TGF $\beta$ ) were found to be elevated after treatment. Moreover, the results showed that tumor blood perfusion improved and osteopontin (OPN) levels increased, whereas vascular endothelial growth factor (VEGF) and TGF $\beta$ levels decreased in tumors from treated mice. All the studied treatments resulted in increased collagen content in the tumor tissue in the early step of tumor progression, and calcitriol caused an increase in collagen content in lung tissue. In addition, in vitro proliferation of 4T1 tumor cells was not found to be affected
\end{abstract}

Correspondence to: Dr Joanna Wietrzyk, Department of Experimental Oncology, Hirszfeld Institute of Immunology and Experimental Therapy, Polish Academy of Sciences, 12 R. Weigla St., 53-114 Wroclaw, Poland

E-mail: wietrzyk@iitd.pan.wroc.pl

Key words: metastasis, calcitriol analog, 4T1 mouse mammary gland cancer, osteopontin, TGF $\beta$ by calcitriol or its analogs in contrast to non-metastatic 67NR cells. Calcitriol and its analogs enhanced the metastatic potential of 4T1 mouse mammary gland cancer by inducing the secretion of OPN probably via host cells. In addition, OPN tumor overexpression prevailed over the decreasing tumor TGF $\beta$ level and blood vessel normalization via tumor VEGF deprivation induced by calcitriol and its analogs. Moreover, the increased plasma TGF $\beta$ and $17 \beta$-estradiol levels contributed to the facilitation of metastatic process.

\section{Introduction}

Approximately $70 \%$ of the breast cancers are estrogen receptor positive $\left(\mathrm{ER}^{+}\right)$and are responsive to endocrine therapy (1). The hormonal drugs used to treat $\mathrm{ER}^{+}$breast cancers have been designed to antagonize the mitogenic effects of estrogens, which include selective estrogen receptor modulators (SERMs) such as tamoxifen and raloxifene that bind to the ER and act as antagonists in the breast; selective estrogen receptor downregulators (SERDs) such as fulvestrant that bind to and target ER for degradation; and aromatase inhibitors (AIs) that inhibit the activity of aromatase, an enzyme that catalyzes the synthesis of estrogens from androgenic precursors (2). Currently, AIs are the first-line therapy used to prevent breast cancer progression in postmenopausal women following primary therapy $(2,3)$. Breast cancer therapies that reduce estrogen levels (e.g., oophorectomy, chemotherapy, and AIs) increase bone resorption without a corresponding increase in bone formation $(4,5)$. The loss of bone mineral density in cancer-associated bone diseases result from the direct or systemic effects of the tumor in addition to the therapies used to treat the primary disease. It may be related to the local effects of metastatic deposits in bone and/or to the generalized bone loss from tumor-produced, systemically circulating, bone-resorbing hormones or cytokines. These comprise parathyroid hormone-related protein (PTHrP) or tumor stimulated secretion by the osteoblast of local bone resorbing factors such as receptor activator of nuclear factor $\kappa \mathrm{B}$ ligand (RANKL), 
interleukin (IL)-6, or IL-3. In some tumors, more than one mechanism may be involved (6). To overcome the problems with failed calcium homeostasis, several issues have been proposed. One of them is the addition of bisphosphonates to mammary gland cancer treatment protocols $(7,8)$. Another is the use of vitamin D during treatment. Many researchers during preclinical studies and clinical observations hypothesized that the addition of vitamin D or its analogs in the breast cancer treatment based on SERMs or AIs improves the efficacy of chemotherapy, among others alleviating patients from the musculoskeletal and joint pain (9-11).

Low vitamin D status, measured in terms of the biomarker 25-hydroxyvitamin D $\left(25-\mathrm{OH}-\mathrm{D}_{3}\right)$, is often considered as the risk factor for breast cancer and has prognostic significance as it is involved in the development of cancer and in interactions with breast cancer treatments (12). The relationship between vitamin D deficiency and breast cancer is rather common and correlated with all clinical parameters such as incidence of tumor, tumor biology, prognosis, and antineoplastic treatment tolerance (13). Vitamin D deficiency increases after adjuvant cancer therapy, which alters bone metabolism in patients with breast cancer thereby increasing the risk of osteoporosis $(14,15)$. Moreover, some studies have demonstrated a high prevalence of vitamin D deficiency in women with ER-negative, progesterone receptor-negative (PR), and human epidermal growth factor receptor 2 (HER2)-negative breast cancers. It is postulated that correction of vitamin D deficiency in these women represents a reasonable but as yet, untested, strategy to delay recurrence and extend survival $(16,17)$.

Vitamin D receptor (VDR) is present in almost all tissues and cells in the human body. Calcitriol, a hormonally active form of vitamin $\mathrm{D}_{3}\left(1,25\right.$-dihydroxyvitamin $\left.\mathrm{D}_{3} ; 1,25(\mathrm{OH})_{2} \mathrm{D}_{3}\right)$, is primarily known for its role in bone mineralization and calcium homeostasis. In addition, several studies have revealed that calcitriol is important in immunomodulation, regulation of inflammation and cytokines, cell proliferation, cell differentiation, apoptosis, and angiogenesis (reviewed in refs. 12,13,18). However, calcemic activity and subsequent risk of hypercalcemia caused by calcitriol treatment has limited its usage in anticancer therapy; therefore, currently, many researchers are focusing on the synthesis of new analogs with balanced calcemic effect and antiproliferative activities. Vitamin $\mathrm{D}_{3}$ metabolite used in this study, $(24 R)$-1,24-dihydroxyvitamin $\mathrm{D}_{3}$ (tacalcitol; 1,24(OH) $)_{2} \mathrm{D}_{3}$; PRI-2191), is physiologically formed via microsomal $\mathrm{C}-24$ hydroxylation process. This process is alternative to $\mathrm{C}-25$ hydroxylation, which leads to the formation of calcitriol. Both calcitriol and tacalcitol are hydroxylated to the less active metabolite $1,24,25(\mathrm{OH})_{3} \mathrm{D}_{3}$. Tacalcitol inhibits proliferation and induces differentiation of epidermal mouse and human keratinocytes. It also binds to the VDR with the affinity higher or similar to that of calcitriol but shows weaker induction of hypercalcemia than calcitriol (19-21). However, the geometric analogs of vitamin $\mathrm{D}$ with the reversed $(5 E, 7 E)$ geometry of the triene system were reported by our (22-24) and other laboratories (25) to show the enhanced biological activity when compared to the natural $(5 Z, 7 E)$ vitamin D. We demonstrated a higher antiproliferative activity of synthetic tacalcitol, PRI-2191, when compared to calcitriol against various cancer cell lines, and we showed that this effect is attributed to the induction of cancer cell differentiation. We also showed the in vitro and in vivo improvement of the activity of a range of anticancer drugs against human and murine cancer cells with concomitant use of vitamin D (20-23,26-31).

For the vast majority of cancer-related deaths, drug resistance and irremovable metastatic lesions are responsible. Metastasis results from the numerous interactions between cancer cells, hematopoietic stem cells, and normal cells within the microenvironment of the primary tumor and metastasis target organ. These interactions are in turn influenced by multiple endocrine, paracrine, and physical factors (32). Bone-targeted treatments may modify the course of the disease via both direct and indirect effects on this 'vicious cycle' of growth factor and cytokine signaling between tumor and normal cells $(5,8)$.

Therefore, in this study, we aimed to evaluate the impact of calcitriol and its low-calcemic analogs on the mammary gland tumor growth and metastasis. To this purpose, we used 4T1 mouse metastatic mammary gland cancer cells because the in vitro proliferation of these cells is not affected by calcitriol or its analogs. We hypothesized that the enhancement of metastatic process by calcitriol and its analogs is related to the impact on tumor microenvironment including tumor vasculature.

\section{Materials and methods}

Compounds. Calcitriol $\left(1,25(\mathrm{OH})_{2} \mathrm{D}_{3}\right)$ and its analogs, namely, PRI-2191 and PRI-2205 are certified synthetic materials obtained from the Pharmaceutical Research Institute, Warsaw, Poland. Samples of the compounds were stored in amber ampoules under argon at $-20^{\circ} \mathrm{C}$. Prior to usage, in case of in vitro studies, compounds were dissolved in $99.8 \%$ ethanol to a concentration of $10^{-4} \mathrm{M}$ and subsequently diluted in culture medium to reach appropriate concentration. For animal experiments, compounds were dissolved in $99.8 \%$ ethanol and then diluted in $80 \%$ propylene glycol (PEG) to reach the required concentrations. All compounds were freshly prepared each day prior to administration. The preparation and storage of the tested compounds was performed according to the manufacturer's instructions (the Pharmaceutical Research Institute) and literature data $(23,33)$. Tested compounds were administered subcutaneously (s.c.) to mice in a volume of $5 \mu \mathrm{l} / \mathrm{g}$ body weight (Fig. 1).

Cells and cell line culture. The mouse mammary adenocarcinoma 4T1 cells were obtained from American Type Culture Collection (ATCC, Rockville, MD, USA) and the 67NR (non-metastatic counterparts of 4T1) cells were received from Barbara Ann Karmanos Cancer Institute, Detroit, MI, USA. The cells were used in experiments immediately after obtaining.

The 4T1 cell line was maintained in a mixture of RPMI-1640 and Opti-MEM medium (1:1, Gibco, Scotland, UK) adjusted to contain $3.5 \mathrm{~g} / 1$ glucose, $2 \mathrm{mM}$ L-glutamine and $0.5 \mathrm{mM}$ sodium pyruvate (Sigma-Aldrich Chemie $\mathrm{GmbH}$, Steinheim, Germany) with 5\% fetal bovine serum (Hyclone, GE Healthcare, UK). The 67NR cells were cultured in Dulbecco's modified Eagle's medium (DMEM; Gibco) with $10 \%$ calf bovine serum (CBS; ATCC), 1\% amino acid, and $2 \mathrm{mM}$ L-glutamine (Sigma-Aldrich Chemie $\mathrm{GmbH}$ ). Both culture 


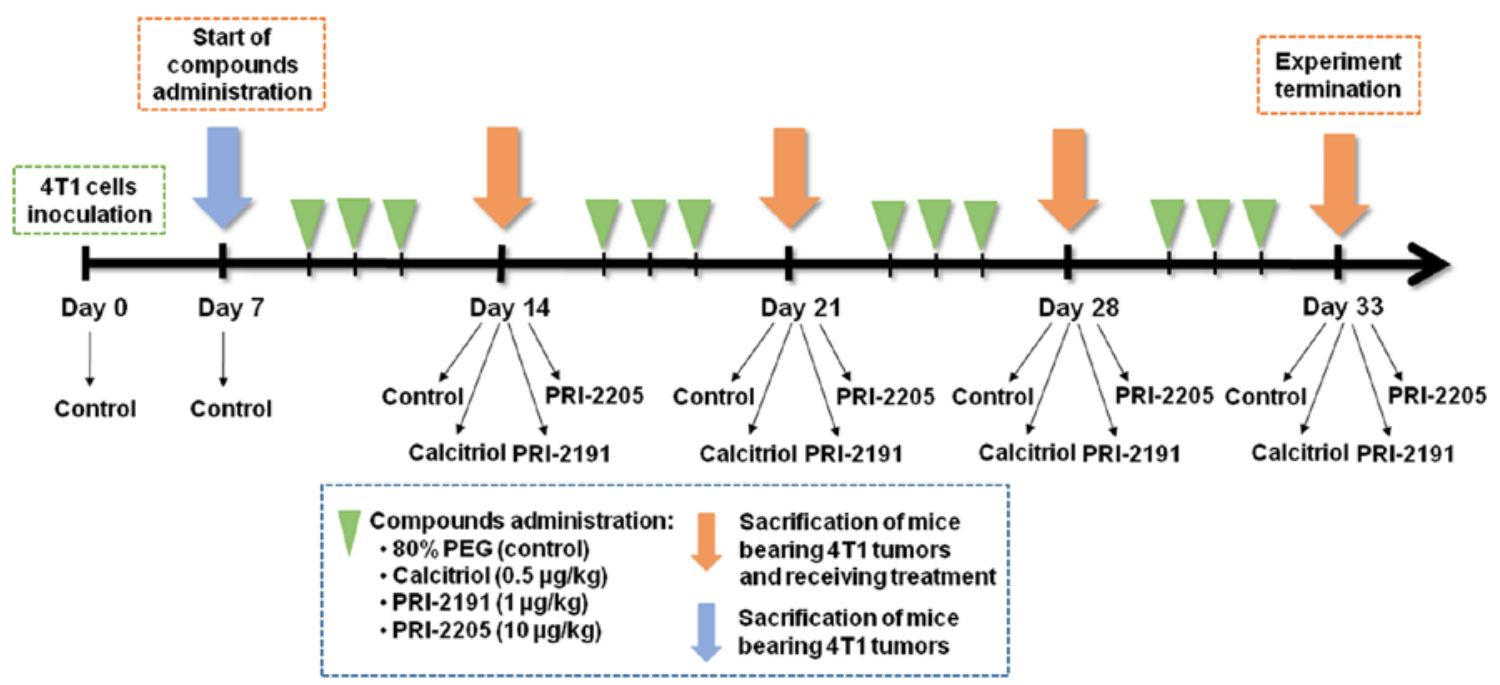

Figure 1. The scheme of in vivo experiments. The effect of calcitriol and its analogs on the growth and metastasis of $4 \mathrm{~T} 1$ mouse mammary gland cancer was investigated at various stages of tumor progression (days 14, 21, 28 and 33). Additional controls were also used: healthy mice (assigned as day 0) and mice with implanted tumors euthanized on the day when the vitamin D derivatives began to be administered (day 7). The control group from day 7 was included to monitor the condition of the body at the start of the treatment. Some of the analysis was performed on two various days: 14 or 21 (as an early stage) and 28 or 33 (as an late stage of tumor progression).

media were supplemented with $100 \mathrm{U} / \mathrm{ml}$ penicillin (Polfa Tarchomin S.A., Warsaw, Poland) and $100 \mu \mathrm{g} / \mathrm{ml}$ streptomycin (Sigma-Aldrich Chemie $\mathrm{GmbH}$ ). The cells were grown at $37^{\circ} \mathrm{C}$ in a humid atmosphere saturated with $5 \% \mathrm{CO}_{2}$.

Mice. BALB/c female, 6-8-week old mice, weighing 20-25 g, obtained from the Center of Experimental Medicine of the Medical University of Bialystok (Bialystok, Poland), were maintained in specific pathogen-free conditions.

All experiments were performed according to EU Directive 2010/63/EU on the protection of animals used for scientific purposes and were approved by the first Local Committee for Experiments with the Use of Laboratory Animals, Wroclaw, Poland (no of permission: 40/2014).

Design of the in vivo experiments. BALB/c female mice were orthotopically inoculated into the right mammary fat pad with $1 \times 10^{4}$ viable $4 \mathrm{~T} 1$ tumor cells per mouse in $0.05 \mathrm{ml}$ Hanks solution and then randomly divided into groups receiving appropriate treatment. Vitamin D analogs were administered subcutaneously (s.c.) thrice a week starting from day 7 after tumor cell inoculation. The single dose of compounds was as follows: calcitriol, $0.5 \mu \mathrm{g} / \mathrm{kg}$; PRI-2191, $1.0 \mu \mathrm{g} / \mathrm{kg}$; and PRI-2205, $10.0 \mu \mathrm{g} / \mathrm{kg}$.

Blood was harvested on the days 0 (before tumor inoculation), 7 (before treatment), 14 (micro-metastases observed (34), 21,28 , and 33 after the inoculation of 4T1 cells (day of tumor inoculation assigned as day 0 ). The mice were anesthetized with 3-5\% (v/v) mixture of isoflurane (Aerrane isofluranum; Baxter, Canada) in synthetic air $(200 \mathrm{ml} / \mathrm{min})$ prior to sacrificing the animals. The tumors, lungs, and thoracic aortas were harvested for further analyzes (Fig. 1). Following additional controls were also used: healthy mice (assigned as day 0) and mice with implanted tumors euthanized on the day when the vitamin D derivatives began to be administered (day 7). The control group from day 7 was included to monitor the condition of the body at the start of the treatment. Some of analyses were performed on two different days: 14 or 21 (as an early stage of tumor progression) and 28 or 33 (as a late stage of tumor progression).

Evaluation of the therapeutic effect. Tumor volume was calculated using the formula $\left(a^{2} \mathrm{x} b\right) / 2$, where $a=$ shorter tumor diameter in $\mathrm{mm}$ and $b=$ longer tumor diameter in $\mathrm{mm}$. Tumors were measured thrice a week. Mice were sacrificed when the tumor volume exceeded $2,000 \mathrm{~mm}^{3}$. Multiple tumors were not observed in our study. Metastases were counted in the lungs fixed in $4 \%$ buffered formalin by two independent examiners and mean value of those counts from two independent experiments is presented.

Body weight change $(B W C)$. The average $\mathrm{BWC}$ in all groups was calculated based on the following formula: $B W C=(A B W \mathrm{n} / A B W 1) \times 100-100 \%$, where $A B W \mathrm{n}$ is the average body weight on the $n^{\text {th }}$ day of the experiment (during treatment) and $A B W 1$ is the average body weight on the first day of treatment. The body weight of experimental animals was measured thrice per week throughout the study. We considered the treatment to be toxic if the BWC was found to be decreased by $\sim 20 \%$ in two successive measurements. However, the experiments were terminated when body weight loss did not reach $20 \%$ in any of the mice.

Calcemic activity. Calcium level was measured in each individual plasma sample using the Cobas c $111 \mathrm{z}$ ISE (Roche Diagnostics Ltd., Rotkreuz, Switzerland) device.

Evaluation of tumor angiogenesis. The influence of calcitriol and its analogs on tumor angiogenesis was evaluated by means of ultrasound imaging of tumor perfusion.

For the ultrasound imaging MicroMarker ${ }^{\mathrm{TM}}$ Contrast Agent (VisualSonics, Ontario, Canada) was prepared according to the manufacturer's instructions. Animals were anesthetized with a 2-3\% (v/v) mixture of isoflurane (Aerrane isofluranum; 
Baxter) in synthetic air $(200 \mathrm{ml} / \mathrm{min})$ and placed on the animal handling station equipped with an individual mask providing $1.5-2 \%(\mathrm{v} / \mathrm{v})$ mixture of isoflurane and synthetic air. The position of the handling station was adjusted so that the central section of the tumor was being visualized and contrast agent was injected into the tail vein of the animal. Signal of the contrast marker accumulating in the tumor tissue was recorded using the probe of 13-24 MHz frequency (MS250, VisualSonics). Next, the peak-enhancement [contrast mean power as l.a.u. (linear arbitrary units)] and time-to-peak (sec) parameters were calculated using the Vevo LAB 1.7.1 Software (VisualSonics).

Immunohistochemical staining of aorta sections. For the double immunohistochemistry sequential staining of thoracic aorta (isolated from mice on the days 7, 14, 21, 28 or 33 and from healthy, non-treated animals) sections were fixed in buffered formalin and then cut into $4-\mu \mathrm{m}$ thick slices that were subsequently dewaxed and rehydrated through gradient of Unyhol and Unyhol Plus (Bio-Optica, Mediolan, Italy). Antigen retrieval was performed by heating in Tris-EDTA, $\mathrm{pH} 9.0$ (Institute of Immunology and Experimental Therapy PAN, Wrocław, Poland) at $96^{\circ} \mathrm{C}$ for $45 \mathrm{~min}$. Endogenous peroxidase and phosphatase activity was quenched by incubating with Dako Dual Endogenous systems (Dako Cytomation Poland, Gdynia, Poland) for $10 \mathrm{~min}$. Subsequently, sections of aorta were incubated with primary antibodies described in Table I.

Antigen-antibody binding was detected using Dako Real EnVision Detection Systems Peroxidase or by Dako Real Detection Alkaline Phosphatase both from Dako Cytomation Poland, according to the manufacturer's instructions. Counterstaining was performed using Gill's III hematoxylin (Merck Millipore, Darmstadt, Germany), and the specimen was secured with a coverslip using Dako Faramount Aqueous Mounting Medium (Dako Cytomation Poland).

Microscopic examination and photographs were captured using a bright field microscope (Olympus CX41) connected with a camera equipped with Olympus Stream Image Analysis Software (Olympus Europe Holding GmBH, Hamburg, Germany). Blinded microscopic examination was performed at magnifications (x10 and x100) and described according to the below scheme: 0 , no staining; $1+$, delicate staining; $2+$, average color staining; $3+$, intense color staining; $4+$, bright color staining.

Masson's trichrome staining for collagen fibers of tumor and lung tissue. Tissues that were dewaxed and rehydrated in a descending alcohol series were incubated with Weigert's iron hematoxylin nuclear staining solution for $5 \mathrm{~min}$ (Merck Millipore, Darmstadt, Germany). After 5 min of flushing in tap water, slides were submerged in $1 \%$ acetic acid for $3 \mathrm{~min}$. Subsequently, the sections were immersed respectively in Azoploxine solution for cytoplasm dyeing (5 min), Tungstophosphoric acid orange $\mathrm{G}$ solution for erythrocytes staining (1 min), and Light green SF solution for collagen and connective tissue visualization ( $5 \mathrm{~min}$ ). The slides were washed in $1 \%$ acetic acid between each staining procedure for $3 \mathrm{~min}$ (Masson-Goldner staining kit, Merck Millipore, Darmstadt, Germany). In the last step, slides were washed in $1 \%$ acetic acid for an additional $5 \mathrm{~min}$ and left to dry. Afterwards histo-
Table I. Antibodies and detection systems used for aorta immunohistochemistry.

\begin{tabular}{lll}
\hline Antibody (source) & \multicolumn{1}{c}{ Antigen } & $\begin{array}{c}\text { Antibody } \\
\text { dilution/ } \\
\text { duration of } \\
\text { incubation }\end{array}$ \\
\hline Rabbit polyclonal (Abcam,, & CD31 (PECAM) & $1: 50 / 1 \mathrm{~h}$ \\
Cambridge, UK) & CD105 (endoglin) & $1: 1,000 / 1 \mathrm{~h}$ \\
& vWF & $1: 100 / 1 \mathrm{~h}$ \\
& $\alpha$ SMA & $1: 100 / 1 \mathrm{~h}$ \\
\hline
\end{tabular}

Table II. Scoring of staining for collagen in lung tissue.

Score for collagen staining

Day after tumor Control Calcitriol PRI-2191 PRI-2205 transplantation

$\begin{array}{lcccc}\text { Day } 0 & +++ & & & \\ \text { Day } 7 & +++ & & & \\ \text { Day } 14 & ++ & +++ & ++ & +/++ \\ \text { Day } 21 & ++ & +/++ & ++ & ++ \\ \text { Day } 28 & ++ & +++/++++ & +/++ & ++\end{array}$

Semiquantitative evaluation of collagen fibers were based on its presence of a small level $(+)$, the medium $(++)$, significant $(+++)$ and very abundant $(++++)$

logical slides were covered with non-aqueous mounting agent (Neo-Mount anhydrous mounting medium; Merck KGaA, Germany) and a cover glass for further analysis.

Microscopic examination and photographs were made using a bright field microscope (Olympus CX41) connected with camera equipped with Olympus Stream Image Analysis software (Olympus Europe Holding GmBH). Blinded microscopic examination was performed at 2 magnifications (x10 and $\mathrm{x} 40$ ) and described according to the scoring described in Table II and figure legends.

Mouse tumor invasion/metastasis PCR array. Total RNA of tumor tissue was extracted using TRIzol (TRI reagent; Sigma-Aldrich) according to the manufacturer's instructions. RNA quantity and purity were determined spectrophotometrically at 260 nm using NanoDrop 2000 (Thermo Fisher Scientific, Waltham, MA, USA) and the quality of RNA was verified by agarose electrophoresis. Reverse transcription was performed using iScript cDNA Synthesis kit (Bio-Rad, Hercules, CA, USA). Real-time quantitative PCR of total cDNA was executed by ViiA ${ }^{\text {TM }} 7$ Real-Time PCR system (Thermo Fisher Scientific) with SYBR green chemistry (Qiagen, Hilden, Germany). Mouse Tumor Invasion/Metastasis PCR Array Library (MTIM-1) was purchased from Real-Time Primers (Elkins Park, PA, USA). The array contained 88 primers for genes associated with the invasion or metastasis process and eight control genes. All genes available within this PCR array are listed in Table III. All PCR amplification cycles were performed at $95^{\circ} \mathrm{C}$ for 
Table III. List of genes evaluated using mouse tumor invasion/ metastasis PCR array library (MTIM-1).

\begin{tabular}{|c|c|c|c|}
\hline & & \\
\hline Symbol & Name & & \\
\hline Adamts1 & ADAM metallopeptidase & Map2k4 & Mitogen-activated protein kinase kinase 4 \\
\hline Aldh3al & Aldehyde dehydrogenase 3 family, member A1 & Map2kJ & Mitogen-activated protein kinase kinase 5 \\
\hline Angpt1 & Angiopoietin 1 & MapzkI & Mitogen-activated protein kinase kinase 7 \\
\hline Angptl4 & Angiopoietin-like 4 & Mcam & Melanoma cell adhesion molecule \\
\hline 10 & Angroporeth-11ке 4 & Met & Met proto-oncogene (hepatocyte growth factor \\
\hline Casp8 & Caspase 8 , apoptosis-related cysteine peptidase & & receptor) \\
\hline Ccne2 & Cyclin E2 & Metap2 & Methionyl aminopeptidase 2 \\
\hline Ccr 7 & Chemokine (C-C motif) receptor 7 & Mmpl & Matrix metallopeptidase 1 (interstitial collagenase) \\
\hline Cd44 & CD44 molecule (Indian blood group) & Mmp10 & Matrix metallopeptidase 10 (stromelysin 2) \\
\hline$C d 82$ & CD82 antigen & Mmpl1 & Matrix metallopeptidase 11 (stromelysin 3) \\
\hline Cdhl & Cadherin 1, type 1, E-cadherin (epithelial) & Mmpl3 & Matrix metallopeptidase 13 (collagenase 3 ) \\
\hline Cdh11 & Cadherin 11, type 2, OB-cadherin (osteoblast) & Mmpl4 & Matrix metallopeptidase 14 (membrane-inserted) \\
\hline$C d h 2$ & Cadherin 2, type $1, \mathrm{~N}$-cadherin & Mmp2 & Matrix metallopeptidase 2 \\
\hline Cdh6 & Cadherin 6 & Mmp7 & Matrix metallopeptidase 7 (matrilysin, uterine) \\
\hline Cldn7 & Claudin 7 & Myc & V-myc myelocytomatosis viral oncogene homolog \\
\hline Collal & Collagen, type I, $\alpha 1$ & Nedd9 & Neural precursor cell expressed, \\
\hline Col4a2 & Collagen, type IV, $\alpha 2$ & & dev. downregulated 9 \\
\hline Col6al & Collagen, type VI, $\alpha 1$ & $N f 2$ & Neurofibromin 2 (merlin) \\
\hline Csf1 & Colony stimulating factor 1 & Nme1 & Non-metastatic cells 1 , protein (NM23A) \\
\hline Csf 2 & Colony stimulating factor 2 & Nme2 & Non-metastatic cells 2 , protein \\
\hline Csf3 & Colony stimulating factor 3 & Nme4 & Non-metastatic cells 4 , protein \\
\hline Cst7 & Cystatin F (leukocystatin) & $\operatorname{Pax} 5$ & Paired box 5 \\
\hline$C t g f$ & Connective tissue growth factor & $P d g f a$ & Platelet-derived growth factor $\alpha$ polypeptide \\
\hline$C t s b$ & Cathepsin B & Plaur & Plasminogen activator, urokinase receptor \\
\hline Ctsd & Cathepsin D & Ptgs 2 & Prostaglandin-endoperoxide synthase 2 \\
\hline Ctsk & Cathepsin K & Runxl & Runt-related transcription factor 1 \\
\hline Ctsll & Cathepsin L-like 3 & Serpine1 & Serpin peptidase inhibitor, clade E \\
\hline Cxcll & Chemokine (C-X-C motif) ligand 1 & Serpinb5 & Serpin peptidase inhibitor, clade B5 \\
\hline Cxcl13 & Chemokine (C-X-C motif) ligand 13 & Sox4 & SRY (sex determining region Y)-box 4 \\
\hline Cxcr4 & Chemokine (C-X-C motif) receptor 4 & & Secreted protein, acidic, cysteine-rich \\
\hline Cxcr6 & Chemokine (C-X-C motif) receptor 6 & & (osteonectin) \\
\hline Drg 1 & Developmentally regulated GTP binding protein 1 & Sppl 1 & Secreted phosphoprotein 1 \\
\hline Ereg & Epiregulin & 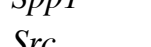 & V-src sarcoma viral oncogene homolog (avian) \\
\hline Fgf8 & Fibroblast growth factor 8 (androgen-induced) & & V-src sarcoma viral oncogene homolog (avian) \\
\hline Flt1 & Fms-related tyrosine kinase & & \\
\hline Flt4 & Fms-related tyrosine kinase 4 & $1 g f b 1$ & Transforming growth factor, $\beta 1$ \\
\hline Gpi & Glucose phosphate isomerase & Timpl & TIMP metallopeptidase inhibitor 1 \\
\hline Gsn & Gelsolin (amyloidosis, Finnish type) & Timp2 & TIMP metallopeptidase inhibitor 2 \\
\hline$H g f$ & Hepatocyte growth factor (hepapoietin A; scatter & Timp3 & TIMP metallopeptidase inhibitor 3 \\
\hline & factor) & Timp4 & TIMP metallopeptidase inhibitor 4 \\
\hline Hifla & Hypoxia inducible factor $1, \alpha$ subunit & Tnc & Tenascin C (hexabrachion) \\
\hline Hmgbl & High-mobility group box 1 & Tp53 & Tumor protein p53 \\
\hline Idl & Inhibitor of DNA binding 1 & Vegfa & Vascular endothelial growth factor A \\
\hline Ill $3 \mathrm{ra} 2$ & Interleukin 13 receptor, $\alpha 2$ & $V e g f b$ & Vascular endothelial growth factor B \\
\hline Isg20 & Interferon stimulated exonuclease gene $20 \mathrm{kDa}$ & $A c t b$ & Actin, $\beta$ \\
\hline & $\begin{array}{l}\text { Interferon stımulated exonuclease gene } 20 \text { KDa } \\
\text { Jagged } 1 \text { (Alagille syndrome) }\end{array}$ & $B 2 m$ & $\beta$-2-microglobulin \\
\hline & Jagged 1 (Alagille syndrome) & Gapd & Glyceraldehyde-3-phosphate dehydrogenase \\
\hline & KiSS-1 metastasis-suppressor & Gusb & Glucuronidase, $\beta$ \\
\hline Klrc2 & Killer cell lectin-like receptor subfamily C, & Hprtl & Hypoxanthine phosphoribosyltransferase 1 \\
\hline & & $P g k$ & Phosphoglycerate kinase 1 \\
\hline Купи & Kynureninase (L-kynurenine hydrolase) & Ppia & Peptidylprolyl isomerase A \\
\hline Ltbp 1 & Latent transforming growth factor $\beta$ binding & Rpl13a & Ribosomal protein L13a \\
\hline
\end{tabular}

Table III. Continued. 
$10 \mathrm{sec}$ and $58^{\circ} \mathrm{C}$ for $45 \mathrm{sec}(50$ cycles). We used $25 \mathrm{ng}$ of cDNA (pooled from 4-5 mice within group) for a single reaction, and each test was performed in duplicate. Fold-change (RQ) of target cDNA was determined by calculating the differences in $\Delta \Delta \mathrm{CT}$ values in reference to phosphoglycerate kinase 1 ( $P g k l)$ by DataAssist 3.01 software (freeware by Applied Biosystems, Foster, CA, USA).

Real-time PCR. Isolation of RNA and synthesis of cDNA was performed as described above. All PCR amplification cycles were performed at $95^{\circ} \mathrm{C}$ for $15 \mathrm{sec}$ and $60^{\circ} \mathrm{C}$ for $1 \mathrm{~min}$ (40 cycles) using primers specific for following genes: Drgl (Mm00492246_m1), Nf2 (Mm00477771_m1), Nedd9 (Mm01324843_m1), Mmp13 (Mm00439491_m1), Mmpl4 (Mm00485054_m1), Sppl (Mm00436767_m1), Flt1 (Mm00438980_m1), Plaur (Mm01149438_m1), Tgfb1 (Mm01178820_m1),pgkl (Mm00435617_m1) with TaqMan chemistry (all from Life Technologies, Carlsbad, CA, USA). We used $25 \mathrm{ng}$ of cDNA for a single reaction, and each sample was performed in triplicate in a single experiment (3 experiments were performed). Fold-change (RQ) of target cDNA was determined by calculating the differences in $\Delta \Delta \mathrm{CT}$ values in reference to phosphoglycerate kinase 1 (Pgkl) by DataAssist 3.01 software (freeware by Applied Biosystems).

\section{Western blotting}

Tissue preparation. Tumor tissue specimens were collected in liquid nitrogen and stored at $-80^{\circ} \mathrm{C}$. To determine the protein expression via western blotting, frozen tumors were mechanically homogenized (Rotilabo, Carl Roth, Karlsruhe, Germany) in RIPA buffer (Sigma-Aldrich Chemie $\mathrm{GmbH}$ ) supplemented with a complete mixture of phosphatase and protease inhibitors (Sigma-Aldrich Chemie $\mathrm{GmbH}$ ) and kept on ice for $25 \mathrm{~min}$. Lysates were purified via microcentrifugation at $14,000 \mathrm{x} g$ for $10 \min$ at $4^{\circ} \mathrm{C}$.

Preparation of cells from in vitro culture. Cultured 4T1 or $67 \mathrm{NR}$ cells were seeded at a density of $3 \times 10^{5}$ cells $/ 4 \mathrm{ml}$ in suitable culture medium on a tissue culture dish. After $2 \mathrm{~h}$ of attachment, cells were exposed to calcitriol or its analogs at a concentration of $100 \mathrm{nM}$ for $72 \mathrm{~h}$. Next, cultures were rinsed with RIPA buffer and a mixture of phosphatase and protease inhibitors. Cells were scraped using cell scrapers and lysates were collected. Cell lysates were incubated on ice for $25 \mathrm{~min}$ and then were microcentrifuged at $10,000 \mathrm{xg}$ for $15 \mathrm{~min}$ at $4^{\circ} \mathrm{C}$.

Protein concentration was determined using a protein assay (DC Protein assay; Bio-Rad Laboratories). Equal amounts of protein (50 $\mu \mathrm{g}$ of cell culture lysates, $100 \mu \mathrm{g}$ of tumor lysates) were mixed with 4X Laemmli sample buffer (Bio-Rad Laboratories). Then, the samples were separated in a $10 \%$ sodium dodecyl sulfate (SDS) polyacrylamide gel and transferred to a polyvinylidene difluoride (PVDF) membrane $(0.45 \mu \mathrm{m}$; Merck Millipore, USA). Membranes were blocked for $1 \mathrm{~h}$ at room temperature in 5\% non-fat dry milk in $0.1 \%$ PBS/Tween-20 (PBST). Next, the membranes were washed $(3 \times 10 \mathrm{~min})$ with $0.1 \%$ PBST and then incubated overnight at $4^{\circ} \mathrm{C}$ with a primary antibody: rabbit anti-VDR,

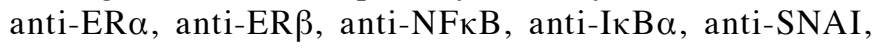
anti-PTEN, anti-CYP24A1, anti-CYP27B1, anti-RXR $\alpha$, anti- $\beta$-catenin polyclonal antibody (Santa Cruz Biotechnology Inc., Santa Cruz, CA, USA), or rabbit anti-E-cadherin and
anti-N-cadherin polyclonal antibody (ProteinTech, Manchester, UK). After incubation, membranes were washed ( $3 \times 10 \mathrm{~min})$ with $0.1 \%$ PBST and incubated for $1 \mathrm{~h}$ with the secondary mouse anti-rabbit immunoglobulin $\mathrm{G}(\mathrm{IgG})$-horseradish peroxidase (HRP) antibody (Santa Cruz Biotechnology Inc.). The membranes were finally washed thrice with $0.1 \%$ PBST and detected by ECL method. Next, to determine the expression of $\beta$-actin, the same membranes (for each tested protein) were incubated with mouse anti- $\beta$-actin-HRP monoclonal antibody for $1 \mathrm{~h}$ at room temperature, washed (3x10 min 0.1\% PBST), and detected by ECL system. Chemiluminescence was visualized using Image Station 4000 (Carestream Health, Rochester, NY, USA). Densitometry analysis of the western blots was performed using Carestream MI Software 5.0.6.20 (Carestream Health). All blots were normalized to that of $\beta$-actin, and the fold-change protein level expression is reported in comparison to that of the $\beta$-actin.

ELISA. For the quantitative determination of $17-\beta$-estradiol, osteopontin (OPN), TGF $\beta$, VEGF, thrombospondin, and 25-OH vitamin D, ELISA kits were used according to the manufacturer's instructions (Demeditec Diagnostics GmbH, Germany; R\&D Systems, Inc., Minneapolis, MN, USA; eBioscience, Vienna, Austria; Thermo Fisher Scientific; Bioassay Technology Laboratory, Shanghai, China; Eagle Biosciences, Nashua, NH, USA, respectively).

Mouse cytokine and protein expression was detected in mouse plasma, tumor homogenates, and in vitro from 4T1/67NR cells culture supernatants. Tumor lysates were prepared as described above (in western blotting methodology).

For in vitro analysis, $4 \mathrm{~T} 1$ or $67 \mathrm{NR}$ cells were seeded in a tissue culture dish at a density of $3 \times 10^{5}$ cells $/ 4 \mathrm{ml}$ or in a 6 -well plate at a density $3 \times 10^{5}$ cells $/ 2 \mathrm{ml}$. Next, after $2 \mathrm{~h}$, the attached cells were exposed to the calcitriol, PRI-2191, or PRI-2205 at a concentration of $100 \mathrm{nM}$ for $6,24,48$ and $72 \mathrm{~h}$. Next, the supernatants were collected and frozen at $-20^{\circ} \mathrm{C}$ until use.

In vitro antiproliferative assay. Antiproliferative tests were performed as previously described (22). Briefly, $24 \mathrm{~h}$ prior to the addition of the tested compounds, 4T1 and 67NR cells were plated in 96-well plates (Sarstedt, Germany) at a density of $1.5 \times 10^{4} / \mathrm{ml}$. To determine the in vitro cytotoxicity of test compounds, the assays were performed after 72-h exposure of the cultured cells to the varying concentrations of tested compounds (total plate incubation time: $96 \mathrm{~h}$ ) using sulforhodamine B (SRB) assay. Both cell lines were exposed to each tested vitamin $\mathrm{D}$ compound at four different concentrations in the range of 1,000-1 nM. The activity of tested agents was compared to the activity of cisplatin, doxorubicin, docetaxel, 5-fluorouracil (all Accord Healthcare Poland, Warsaw, Poland), camptothecin, and tamoxifen (Sigma-Aldrich Chemie $\mathrm{GmbH}$ ). In addition, control wells loaded with either ethanol or DMSO based on the solubility of the tested agents were maintained. Absorbance of each solution was read using Synergy H4 (BioTek Instruments USA) at a wavelength of $540 \mathrm{~nm}$. Entire washing procedure was performed on Biotek EL-406 washing station. The results were calculated as $\mathrm{IC}_{50}$ value (inhibitory concentration $50 \%)$ - the dose $(\mathrm{nM}$ or $\mu \mathrm{g} / \mathrm{ml})$ of tested agent which inhibits proliferation of $50 \%$ of the cancer cell 
A
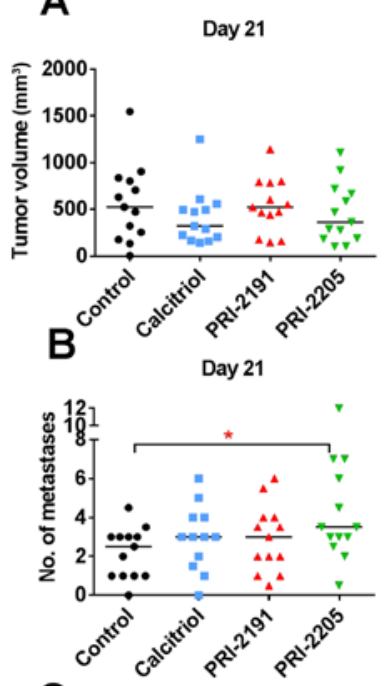

C

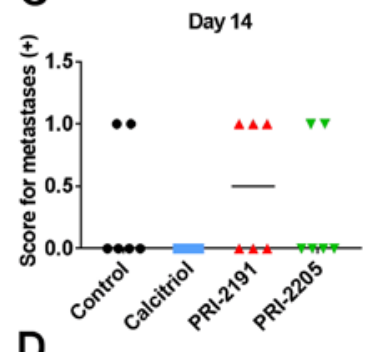

D

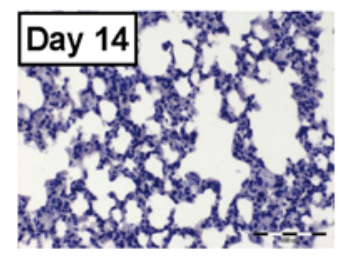

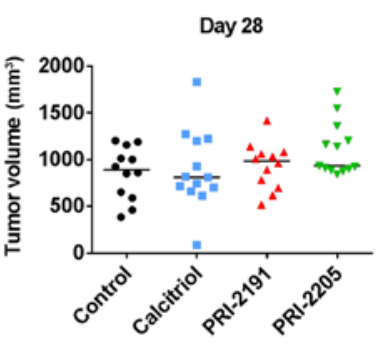

Day 28

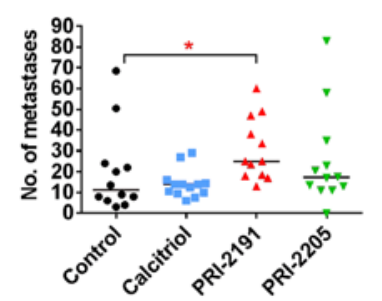

Day 28
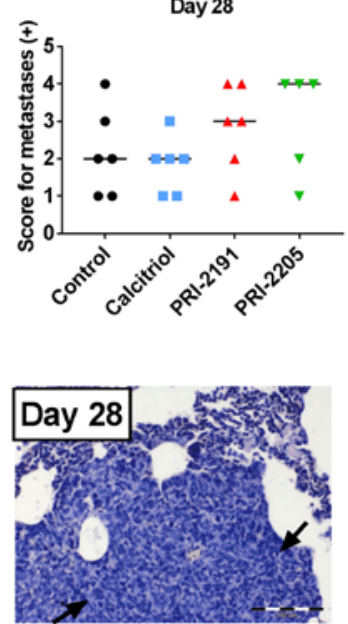

Day 33

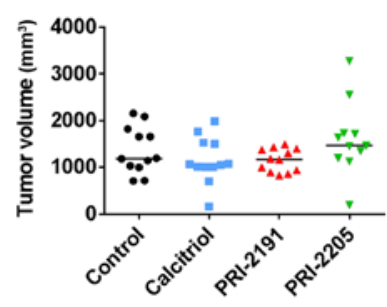

Day 33
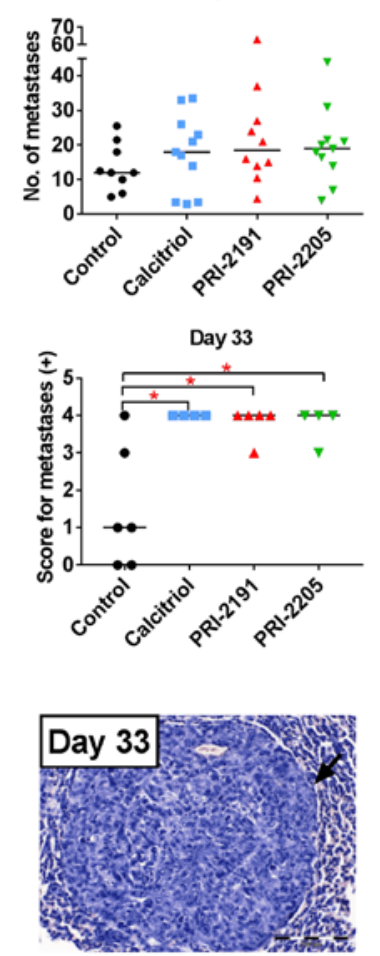

Figure 2. Tumor volume and number of lung metastases in mice bearing 4T1 tumors treated with calcitriol, PRI-2191, and PRI-2205. (A) Tumor volume measured on day 21, 28 and 33 of experiment. (B) Number of lung metastases counted in lungs from two independent experiments. (C) Score for metastases in H\&E stained lungs, days 14, 28 and 33: 0, no metastasis detected; +, 1-3 metastatic foci; ++, 4-7 foci; +++, 8-10 foci; ++++, >10 metastatic foci in lungs. (D) An example of $\mathrm{H} \& \mathrm{E}$ stained lungs on various stages of tumor progression from mice treated with calcitriol. Black arrows indicated tumor nodules. Magnification, x20, scale bar, $100 \mu \mathrm{m}$. Mice were inoculated orthotopically with 4T1 cells on day 0 . From day 7 (7 days after tumor inoculation), vitamin D analogs were administered subcutaneously (s.c.) thrice a week. The single dose of compounds were as follows: calcitriol, $0.5 \mu \mathrm{g} / \mathrm{kg} ; \mathrm{PRI}-2191,1.0 \mu \mathrm{g} / \mathrm{kg} ;$ and PRI-2205, $10.0 \mu \mathrm{g} / \mathrm{kg}$. Number of mice were 9-13 per group. Data were collected from two independent experiments. Data for individual animals are presented with median lines. Statistical analysis: Kruskal-Wallis multiple comparison test. ${ }^{*} \mathrm{P}<0.05$.

population. $\mathrm{IC}_{50}$ values were calculated in Prolab-3 system based on Cheburator 0.4, Dmitry Nevozhay software for each experiment (35). Each compound in each concentration was tested in triplicate in a single experiment, which was repeated at least thrice.

Statistical evaluation. Statistical analysis was performed using Statistica version 10 (StatSoft Inc., USA) or GraphPad Prism 7.01 (GraphPad Software Inc., USA). The assumptions of analysis of variance (ANOVA) were checked using Shapiro-Wilk's normality test and Bartlett's test. Specific tests used for data analysis are indicated in figure legends. $\mathrm{P}<0.05$ was considered to be statistically significant.

\section{Results}

The animal experiments were planned to investigate the effect of calcitriol and its analogs on the growth and metastasis of mammary gland cancer at various stages of its progression. Besides control healthy mice used for comparisons in selected experiments (assigned as day 0), mice were euthanized on day 7 after tumor cells transplantation to monitor the condition of the body at the start of treatment. To analyze the treatment results during tumor progression, we selected the following time-points of observation: day 14 after cells inoculation (7th day of treatment) as the day, when according to the literature data first micro-metastases can be observed in 4T1 tumor model (34). Next observation points were every week until the first signs of health problems: days 21, 28 and 33. The last observation time was shortened because of the observed body weight loss described below.

Calcitriol and its analogs stimulated metastatic spread of 4T1 mammary gland cancer. In two independent experiments, neither calcitriol nor its analogs (PRI-2191 and PRI-2205) influenced primary 4T1 tumor growth significantly (Fig. 2A). 
A
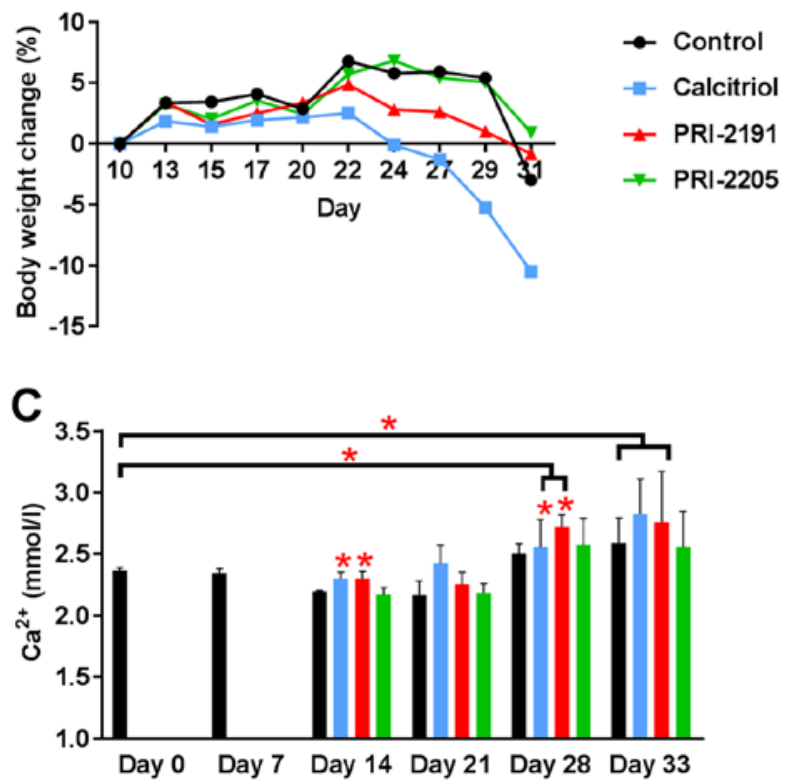

B

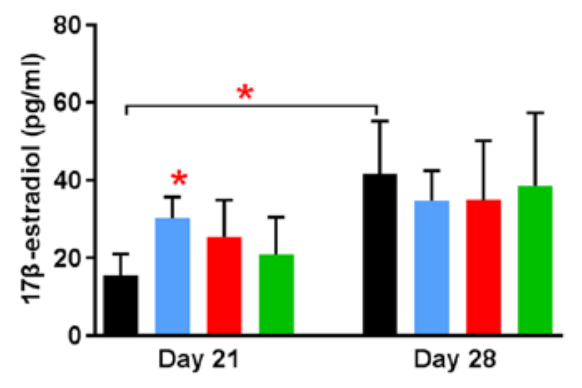

D

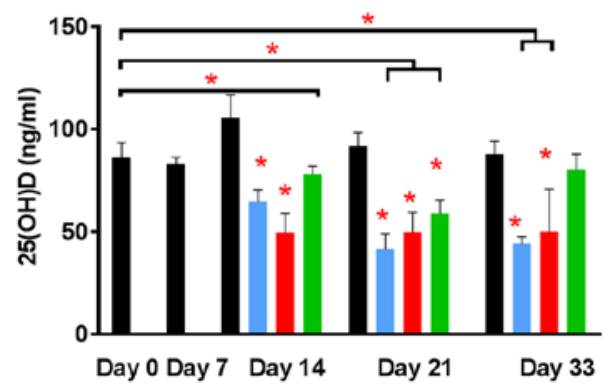

Figure 3. Body weight changes and blood calcium, 17 $\beta$-estradiol, and 25(OH)D level in 4T1 tumor-bearing mice. (A) Body weight changes (BWCs) and (B) $17 \beta$-estradiol, (C) blood calcium, and (D) $25(\mathrm{OH}) \mathrm{D}$ level in mouse plasma. Mice were inoculated orthotopically with $4 \mathrm{~T} 1 \mathrm{cells}$ on day 0 . From day 7 (7 days after tumor inoculation), vitamin D analogs were administered subcutaneously (s.c.) thrice a week. The single dose of compounds was as follows: calcitriol, $0.5 \mu \mathrm{g} / \mathrm{kg} ;$ PRI-2191, $1.0 \mu \mathrm{g} / \mathrm{kg}$; and PRI-2205, $10.0 \mu \mathrm{g} / \mathrm{kg}$. Number of mice were 5-7 per group. D0, control, healthy mice; D7, 4T1 tumor-bearing non-treated mice 7 days after tumor transplantation. Mean values with standard deviation (SD) are presented. Color bars, black, control animals; blue, calcitriol; red, PRI-2191; green, PRI-2205. Statistical analysis: (B) Mann-Whitney U test. (C and D) Dunnett's multiple comparisons test; significant differences are marked on the figure: ${ }^{\mathrm{P}}<0.05$ as compared to control animals on the relevant day of treatment, or as indicated by fastener. The decrease in BWC observed in (A) from day 24 until the last day of measurements is caused by the calcitriol toxicity (blue line). The mean body weight decreased in $\sim 10.5 \%$ when compared to control mice (A). We considered the treatment to be toxic if the BWC decreased by $20 \%$ in two successive measurements.

However, in both experiments, the stimulation of lung metastases resulting from the treatment was observed (Fig. 2B). Metastatic foci in lungs were first macroscopically visible on day 21 after inoculation of the tumor cells. On this day, the number of metastases in mice treated with PRI-2205 $(\mathrm{P}<0.05)$ was almost twice as high as in control animals. On day 28 , the influence of calcitriol on metastasis formation was not observed; however, PRI-2191 and PRI-2205 significantly enhanced the formation of metastases in $127 \%(\mathrm{P}<0.05)$ and $54 \%$, respectively, as compared to the control mice. On day 33, the tendency to stimulate the formation of lung metastasis was observed in mice treated with calcitriol, PRI-2191, and PRI-2205 (50, 54 and $58 \%$ over control, respectively; not significant because of high differences between mice). Histological examination of lung tissue from one of the two conducted experiments showed single metastatic foci on day 14 (in 2 out of 6 in the control group, 0 out of 6 in calcitriol treated, 3 out of 6 in PRI-2191, and 2 out of 6 in PRI-2205 treated mice). On day 33, statistically significant increase of the number of metastatic foci in mice treated with all compounds was observed (Fig. 2C and D).

BWC and blood calcium level were measured throughout the experiment to estimate the toxicity of the treatments used (Fig. 3). The body weight of mice remained unchanged significantly till day 22 in all experimental groups. The kinetics of BWC in control and mice treated with PRI-2191 and PRI-2205 was similar till the end of the experiment. However, from day 24 until the last day of measurements, toxicity of calcitriol was observed in terms of BWC, which decreased in $\sim 10 \%$ of the control mice (Fig. 3A).
From day 28, an increase in calcium level was observed in both control (as a result of tumor progression) and treated mice. On day 33, serum calcium level was found to be significantly higher in control tumor-bearing mice than in healthy mice (day 0; Fig. 3C). Calcitriol and PRI-2191 significantly increased calcium level on days 14 and 28 when compared to relevant control tumor-bearing mice $(\mathrm{P}<0.05)$. The elevation of calcium level was also significant in mice treated with these compounds on days 28 and 33 when compared to healthy animals. In parallel, measurements of $25(\mathrm{OH}) \mathrm{D}$ in plasma showed significant decrease of $25(\mathrm{OH}) \mathrm{D}$ in mice treated with all agents (day 21) or in mice treated with calcitriol or PRI-2191 at all days of measurements (Fig. 3D).

The plasma concentration of $17 \beta$-estradiol was found to be significantly increased in control mice from days 21 to 28 . Calcitriol on day 21 caused increase in plasma $17 \beta$-estradiol level when compared to control mice $(\mathrm{P}<0.05)$. Both analogs showed similar tendency (Fig. 3B).

Calcitriol and its analogs normalized tumor vasculature of $4 T 1$ mammary gland cancer. We estimated the influence of calcitriol and its analogs on tumor angiogenesis. The results of the intravital ultrasound imaging of blood flow in tumor tissue as reflected by peak-enhancement and time-to-peak parameter values indicate that all compounds enhanced tumor blood perfusion (Fig. 4A-C). Calcitriol and its analogs significantly enhanced the time-to-peak parameter (mean value for control mice was $11.59 \mathrm{sec}$ and mean value for mice treated with calcitriol, PRI-2191, and PRI-2205 was 13.76, 13.62 and 


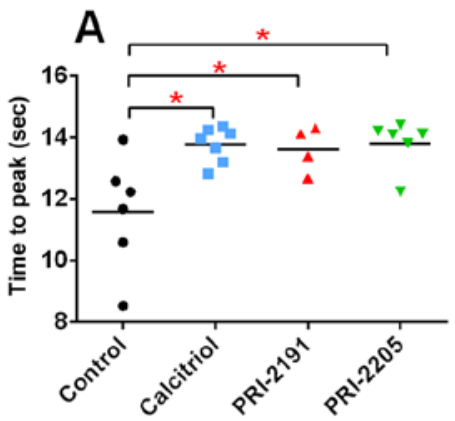

B

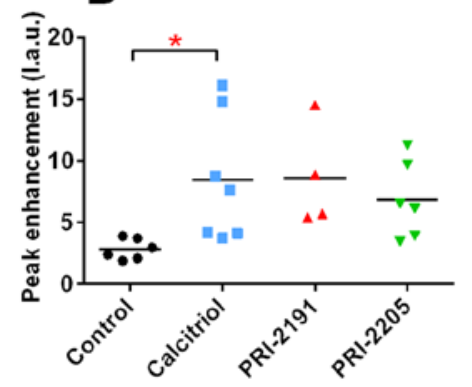

D
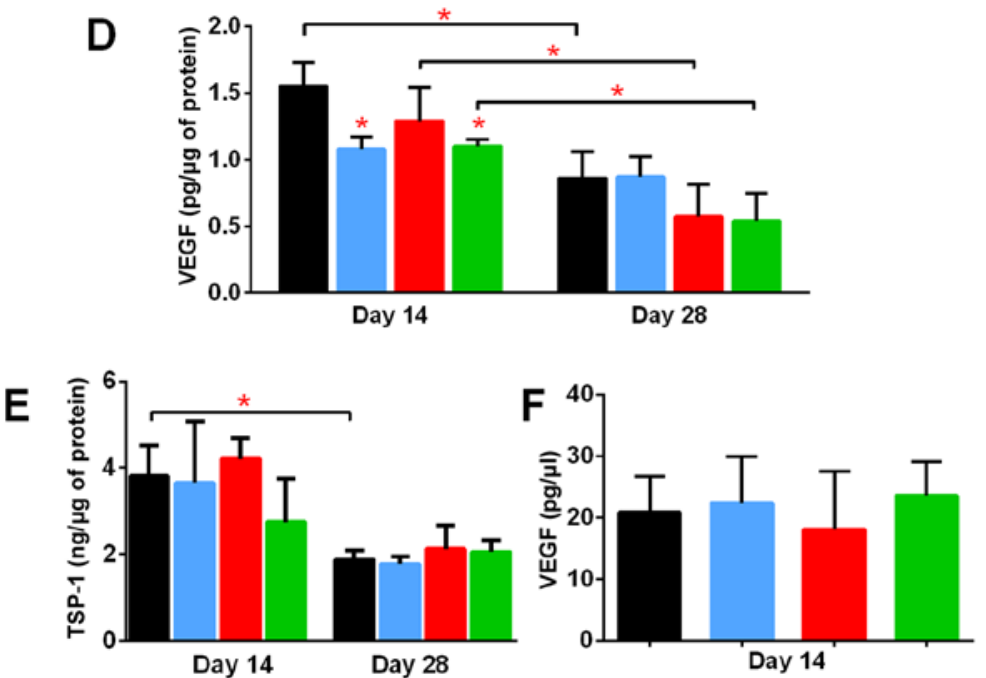

C
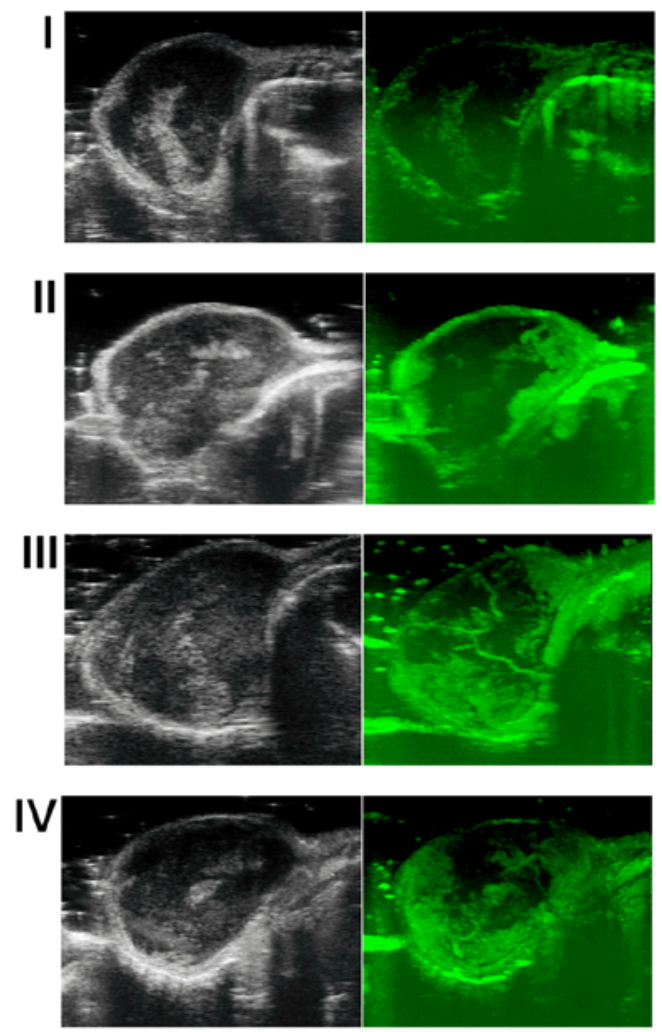

Figure 4. Influence of calcitriol, PRI-2191, and PRI-2205 on angiogenesis of 4T1 tumor. Tumor blood perfusion estimated by ultrasound imaging as (A) time to peak and (B) peak-enhancement values measured on day 24 after 4T1 mammary gland cancer inoculation. (C) Representative images of tumor perfusion taken for (I) control group, (II) mice treated with calcitriol, (III) PRI-2191, and (IV) mice treated with PRI-2205. (D) VEGF level in tumor tissue. (E) Thrombospondin 1 (TSP-1) tumor tissue level. (F) VEGF plasma level measured on day 14. Mice were inoculated orthotopically with 4T1 cells on day 0. From day 7 (7 days after tumor inoculation), vitamin D analogs were administered subcutaneously (s.c.) thrice a week. The single dose of compounds were as follows: calcitriol, $0.5 \mu \mathrm{g} / \mathrm{kg}$; PRI-2191, $1.0 \mu \mathrm{g} / \mathrm{kg}$; and PRI-2205, $10.0 \mu \mathrm{g} / \mathrm{kg}$. Number of mice evaluated were $4-7 \mathrm{per}$ group. Color bars, black, control animals; blue, calcitriol; red, PRI-2191; green, PRI-2205. Data presentation: (A and B) Data for individual animals with median line. (C) Representative ultrasound images: left panel, before; right panel, after contrast inoculation. (D and E) Mean \pm standard deviation. Statistical analysis: (A and B) Dunnett's multiple comparisons test. (D) Tukey's multiple comparison test. (E) Sidak's multiple comparison test. *P<0.05 as compared to control animals on the relevant day of treatment.

$13.81 \mathrm{sec}$, respectively, $\mathrm{P}<0.05$; Fig. 4A). After treatment with calcitriol, we observed statistically significant increase in case of values of peak-enhancement parameter when compared to the control group of animals [8.49 1.a.u. (linear arbitrary units) vs. 2.84 1.a.u.; Fig. 4B].

Simultaneously, we observed a significant decrease in VEGF levels in tumor tissue after treatment with calcitriol $(1.08 \mathrm{pg} / \mu \mathrm{g})$ and PRI-2205 $(1.10 \mathrm{pg} / \mu \mathrm{g})$ on day 14 when compared to the control mice $(1.55 \mathrm{pg} / \mu \mathrm{g} ; \mathrm{P}<0.05)$. On day 28 , we observed statistically significant decrease in VEGF levels in tumor tissue of control mice when compared to day 14. A further decrease in VEGF levels was observed after treatment with PRI-2191 and PRI-2205 on day 28 (Fig. 4D). The levels of thrombospondin 1 (TSP-1), an antiangiogenic factor, in tumor tissue decreased from days 14 to 28 ; however, its levels were not affected by treatment with calcitriol or its analogs (Fig. 4E). VEGF level in plasma on day 14 was not influenced by the treatments used in this study (Fig. 4F).

Induction of OPN mRNA (Sppl) by calcitriol and its analogs during the early phase of tumor progression. To identify the candidate genes that might be regulated by calcitriol and its analogs in the process of enhanced metastatic dissemination of 4T1 cells, polymerase chain reaction (PCR) array screening was performed (88 tested genes listed in Table III). Data were analyzed for transcripts from tumors taken from mice at two time points: on day 14 and on day 28 after $4 \mathrm{~T} 1$ tumor inoculation. We observed the expression of 46 out of 88 genes screened. The candidate genes were selected for further examination based on fold change compared to its expression in non-treated tumors [day 7, relative quantification (RQ) values presented in Table IV]. The expression of selected genes in tumor tissues was confirmed by real-time PCR analysis.

Calcitriol and its analogs downregulated the expression of some genes coding growth factors and their receptors involved in tumor angiogenesis, the expression of which increased during 4T1 tumor progression [vascular endothelial growth factor receptor 1 ( Flt1), transforming growth factor $\beta 1(T g f b 1)]$. However, the expression of connective tissue growth factor $(C \operatorname{tg} f)$ and platelet-derived growth factor $\alpha(P d g f a)$ was increased after treatment with calcitriol and its analogs (Fig. 5A). The expression of type VI collagen $\alpha 1$ (Col6al) and matrix metallopeptidases 13 and 14 (Mmpl3 and $M m p 14$ ) decreased, whereas the expression of $M m p 2$ 
Table IV. The expression of genes associated with tumor invasion or metastasis evaluated in 4T1 tumor tissue after treatment with calcitriol or its analogs.

\begin{tabular}{|c|c|c|c|c|c|c|c|c|}
\hline \multirow[b]{2}{*}{ Gene } & \multicolumn{2}{|c|}{ Control } & \multicolumn{2}{|c|}{ Calcitriol } & \multicolumn{2}{|c|}{ PRI-2191 } & \multicolumn{2}{|c|}{ PRI-2205 } \\
\hline & D14 & D28 & D14 & D28 & D14 & D28 & D14 & D28 \\
\hline Adamtsl & 8.300 & 2.754 & 1.653 & 3.996 & 2.534 & 4.028 & 4.959 & 2.247 \\
\hline Angpt14 & 3.526 & 4.325 & 1.528 & 3.342 & 2.861 & 2.468 & 2.500 & 2.897 \\
\hline Casp8 & 5.738 & 3.931 & 1.368 & 6.865 & 5.412 & 8.016 & 3.174 & 4.734 \\
\hline$C d 82$ & 11.476 & 10.293 & 1.929 & 10.865 & 6.052 & 7.078 & 2.786 & 19.504 \\
\hline$C d h 2$ & 5.481 & 4.407 & 1.680 & 6.547 & 2.697 & 1.434 & 3.685 & 4.377 \\
\hline Cdh6 & 1.201 & 1.030 & 1.249 & 2.244 & 1.588 & 1.928 & 0.394 & 1.578 \\
\hline Collal & 6.035 & 2.921 & 2.069 & 0.362 & 0.899 & 0.486 & 0.750 & 2.647 \\
\hline Col4a2 & 2.637 & 1.809 & 2.193 & 2.434 & 6.010 & 2.839 & 2.444 & 6.133 \\
\hline Col6al & 13.012 & 7.619 & 1.252 & 2.712 & 1.534 & 1.842 & 1.714 & 6.557 \\
\hline Cst7 & 2.669 & 1.666 & 1.801 & 2.727 & 3.533 & 4.933 & 3.064 & 7.574 \\
\hline$C t g f$ & 18.556 & 12.008 & 0.763 & 12.120 & 1.835 & 1.888 & 2.538 & 5.185 \\
\hline$C t s b$ & 2.843 & 2.500 & 15.140 & 0.892 & 0.122 & 0.555 & 0.445 & 0.363 \\
\hline$C t s d$ & 15.520 & 18.011 & 5.140 & 0.107 & 1.989 & 2.080 & 0.928 & 1.434 \\
\hline Ctsll & 6.498 & 18.792 & 4.327 & 4.351 & 0.483 & 4.482 & 1.148 & 1.396 \\
\hline Cxcll & 3.566 & 3.480 & 4.935 & 3.949 & 6.191 & 7.234 & 3.045 & 11.300 \\
\hline Drgl & 5.292 & 3.740 & 1.290 & 5.493 & 4.317 & 1.452 & 1.086 & 2.584 \\
\hline Flt1 & 5.872 & 8.900 & 1.615 & 2.505 & 2.509 & 1.831 & 0.917 & 6.456 \\
\hline Gpi & 2.334 & 1.812 & 3.471 & 3.173 & 5.454 & 3.675 & 2.774 & 4.742 \\
\hline Gsn & 1.297 & 1.001 & 1.154 & 1.683 & 1.628 & 2.128 & 1.282 & 2.010 \\
\hline Idl & 2.855 & 2.186 & 1.637 & 1.940 & 2.016 & 2.671 & 1.800 & 2.287 \\
\hline Isg20 & 10.271 & 13.785 & 11.894 & 14.061 & 3.263 & 10.219 & 2.158 & 14.053 \\
\hline Jag1 & 15.663 & 10.047 & 1.784 & 2.597 & 5.598 & 14.129 & 6.377 & 2.102 \\
\hline Map $2 k 4$ & 11.770 & 10.176 & 1.522 & 20.272 & 2.063 & 4.953 & 2.779 & 3.258 \\
\hline Mcam & 2.307 & 8.493 & 1.969 & 2.567 & 2.687 & 2.396 & 1.241 & 3.739 \\
\hline Metap 2 & 2.103 & 4.064 & 3.050 & 2.800 & 5.150 & 2.149 & 0.694 & 2.286 \\
\hline Mmpl1 & 2.748 & 3.962 & 1.375 & 6.656 & 2.389 & 5.574 & 1.547 & 3.540 \\
\hline Mmpl3 & 15.092 & 6.512 & 10.286 & 4.299 & 3.337 & 4.448 & 4.385 & 6.341 \\
\hline Mmpl4 & 8.438 & 7.808 & 3.079 & 3.122 & 0.959 & 6.057 & 2.347 & 7.366 \\
\hline Mmp2 & 10.257 & 25.839 & 3.043 & 3.718 & 0.801 & 17.339 & 4.869 & 2.932 \\
\hline Nedd9 & 2.397 & 2.421 & 1.531 & 1.521 & 1.444 & 2.846 & 2.414 & 1.673 \\
\hline$N f 2$ & 1.385 & 3.778 & 2.141 & 1.982 & 1.685 & 3.101 & 3.024 & 1.919 \\
\hline Nme 2 & 5.052 & 2.180 & 11.167 & 3.796 & 31.448 & 7.117 & 7.194 & 17.671 \\
\hline Nme4 & 3.300 & 4.548 & 2.309 & 2.692 & 1.340 & 10.143 & 5.289 & 4.507 \\
\hline $\operatorname{Pax} 5$ & 3.510 & 1.350 & 3.781 & 1.025 & 21.864 & 2.887 & 1.547 & 3.213 \\
\hline$P d g f a$ & 1.667 & 2.270 & 2.002 & 1.580 & 2.965 & 8.540 & 3.473 & 1.574 \\
\hline Plaur & 2.109 & 3.874 & 3.297 & 1.785 & 2.146 & 4.060 & 1.998 & 3.030 \\
\hline Ptgs 2 & 5.118 & 2.797 & 3.370 & 2.149 & 2.776 & 7.053 & 5.086 & 2.962 \\
\hline Runxl & 1.982 & 4.925 & 1.420 & 3.090 & 0.747 & 2.129 & 1.540 & 0.521 \\
\hline Serpinel & 1.164 & 0.524 & 2.918 & 0.733 & 1.662 & 0.931 & 1.091 & 0.830 \\
\hline Sparc & 1.237 & 0.486 & 3.572 & 0.545 & 3.355 & 0.798 & 1.319 & 6.911 \\
\hline Sppl & 1.198 & 2.990 & 2.287 & 2.118 & 1.227 & 0.982 & 1.367 & 1.744 \\
\hline Src & 1.846 & 1.898 & 4.773 & 1.321 & 1.676 & 1.769 & 1.927 & 1.547 \\
\hline$T g f b l$ & 3.058 & 5.330 & 4.415 & 1.100 & 0.940 & 1.817 & 1.187 & 2.014 \\
\hline Timpl & 1.248 & 1.303 & 3.395 & 0.987 & 1.362 & 0.655 & 0.891 & 0.583 \\
\hline Timp3 & 0.068 & 0.019 & 0.054 & 0.037 & 0.095 & 0.602 & 0.043 & 0.064 \\
\hline Vegfa & 0.307 & 0.155 & 0.224 & 0.092 & 2.461 & 0.150 & 0.208 & 0.100 \\
\hline
\end{tabular}

Tumors were collected on days 14 and 28 (after inoculation with 4T1 cells) from mice treated with calcitriol or its analogs and control group receiving $80 \%$ propylene glycol (vehicle for vitamin D analogs). Real-time PCR screening was performed using the mouse tumor invasion/ metastasis PCR array library (MTIM-1). From 88 genes available in this array (Table III), the expression for 42 genes was not detected in 4T1 tumor tissue. Data presented as mean relative quantification (RQ) values (calculated from duplicate). Fold-change (RQ) of target cDNA was determined by calculating the differences in $\Delta \Delta C$ T values with reference to phosphoglycerate kinase 1 (Pgk1) by DataAssist v 3.01 software. All PCR amplification cycles were performed at $95^{\circ} \mathrm{C}$ for $10 \mathrm{sec}$ and $58^{\circ} \mathrm{C}$ for $45 \mathrm{sec}$ (50 cycles). We used $25 \mathrm{ng}$ of cDNA for a single reaction, and each test was performed in duplicate. 
A
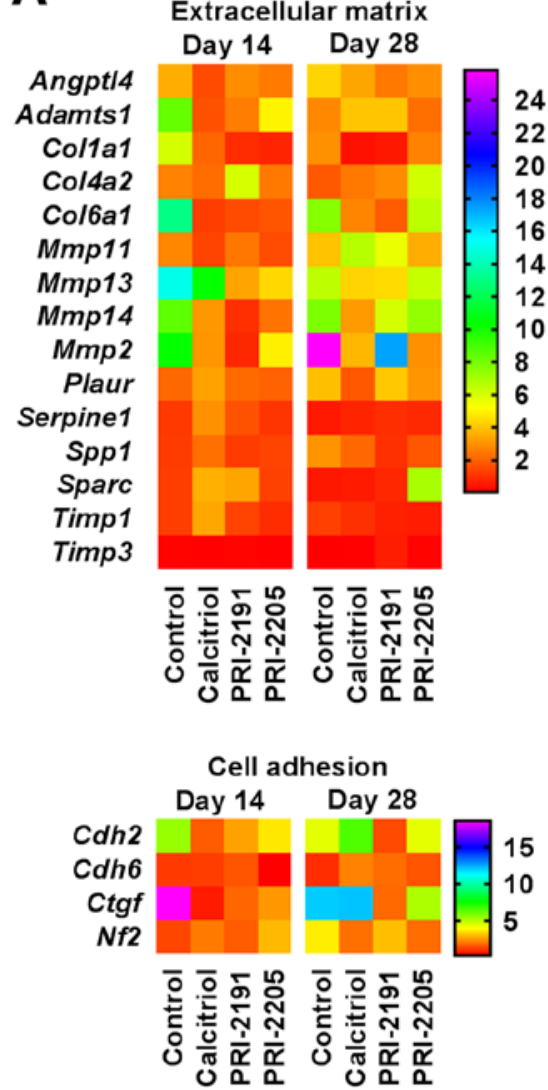

B
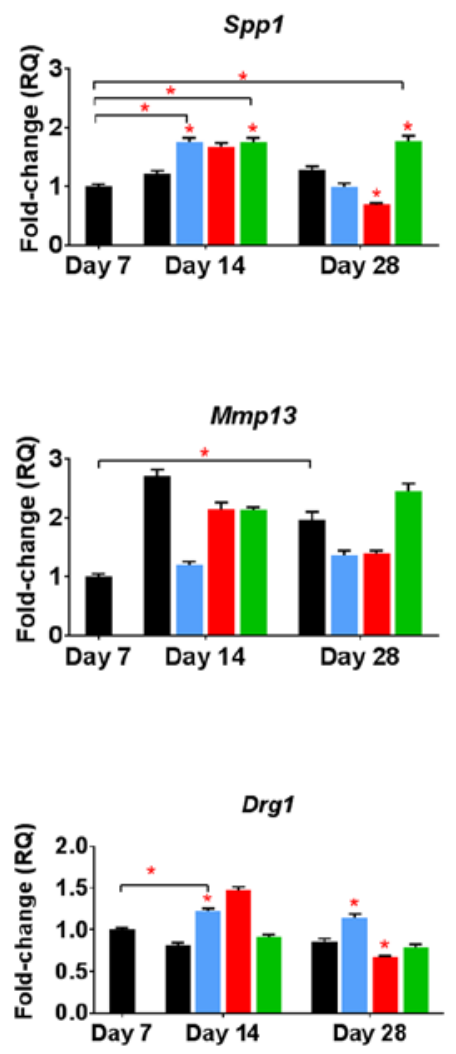

Growth factors \& receptors
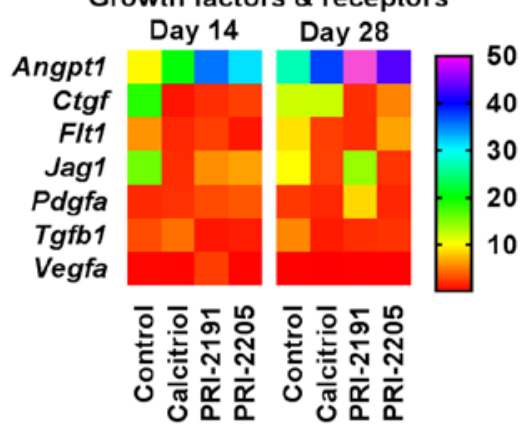

Intracellular protein catabolism
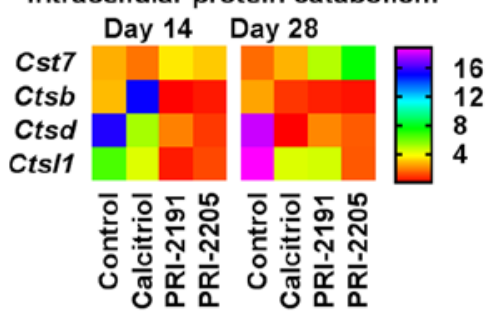

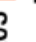

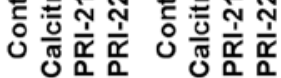
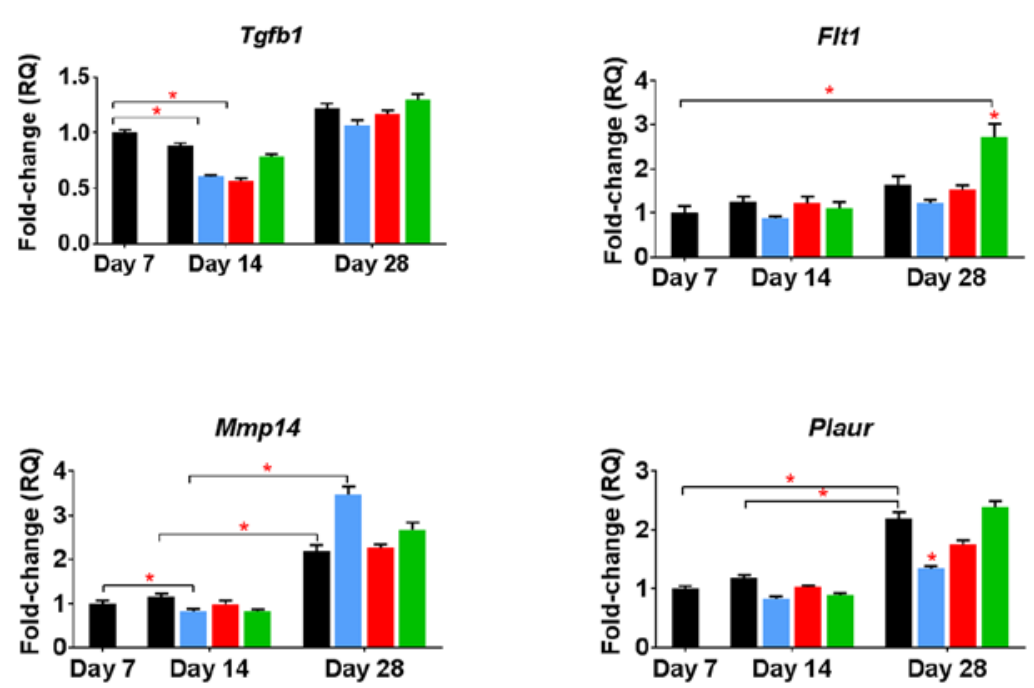

Figure 5. Changes in mRNA expression in tumors from mice treated with calcitriol or its analogs. (A) Screening of genes using real-time polymerase chain reaction correlated with tumor invasion and metastasis. (B) Real-time PCR analysis of nine selected genes. Number of mice evaluated were 3-7 per group. Color bars, black, control animals; blue, calcitriol; red, PRI-2191; green, PRI-2205. Data presentation: (A) Heat maps presenting mean relative quantification (RQ) values from duplicates. (B) Mean \pm standard deviation. Statistical analysis: Kruskal-Wallis multiple comparisons test, ${ }^{*} \mathrm{P}<0.05$ as compared to control animals on the relevant day of treatment or as indicated. 
increased in control tumor tissue between days 14 and 28 of tumor growth. Calcitriol and its analogs showed tendency to reduce the aforementioned gene mRNA levels when compared to control (Fig. 5A). Calcitriol and its analogs also decreased the expression of angiopoietin-like 4 gene (Angptl4; on both days 14 and 28 of measurement) and secreted phosphoprotein 1 (OPN; Sppl; on day 28). Increased expression of non-metastatic cells 2 (Nme2), chemokine (C-X-C motif) ligand 1 (Cxcll), and cystatin F (leukocystatin; Cst7) in tumors from mice treated with all compounds was observed. However, developmentally regulated GTP binding protein 1 (Drgl), cathepsins B and D (Ctsb and $C t s d$ ), and $C t g f$ were downregulated by the administration of calcitriol and its analogs (except $C t s b$ after calcitriol treatment on day 14) (Fig. 5A).

We performed real-time PCR analysis of the following nine selected mRNAs: Drg1, Flt1, Sppl, neurofibromin 2 (merlin; $N f 2$ ), neural precursor cell expressed, dev. downregulated 9 (Nedd9), Mmp13, Mmp14, Tgfb and plasminogen activator, urokinase receptor (Plaur). The expression of $N f 2, N e d d 9$, Mmp13, Mmp14 and Plaur significantly increased during tumor progression; however, calcitriol or its analogs (with the exception of upregulation of Flt1 by PRI-2205 and downregulation of Plaur by calcitriol) did not influence the expression of aforementioned mRNAs significantly. The mRNAs that were significantly influenced by calcitriol and its analogs were Sppl and Drgl. The expression of Sppl was significantly upregulated in tumor tissue by calcitriol and PRI-2205 on day 14 and by PRI-2205 on day 28. PRI-2191 downregulated Sppl on day 28 (Fig. 5B). The expression of Drgl (also known as Nedd3) was increased after treatment with calcitriol on days 14 and 28, but it decreased after treatment with PRI-2191 on day 28. In addition, significant decrease in the expression of $T g f b$ was observed in mice treated with calcitriol and PRI-2191 on day 14 when compared to control mice bearing tumors on day 7 (Fig. 5B).

Selected protein expression in tumors harvested from the mice treated with calcitriol and its analogs. First, we estimated the expression of the following receptors and transcription factors known as typical for calcitriol and/or typical for mammary gland cancer: VDR and retinoid $X$ receptor ( $R X R)$, estrogen receptors $E R \alpha$ and $\beta$, nuclear factor $\kappa \mathrm{B}(\mathrm{NF} \kappa \mathrm{B})$, inhibitor of $\kappa \mathrm{B}$ $(\mathrm{I} \kappa \mathrm{B})$, phosphatase and tensin homolog (PTEN), snail family transcriptional repressor 1 (SNAI1), as well as E- and $\mathrm{N}$-cadherin - markers of epithelial to mesenchymal transition (EMT).

VDR level increased during 4T1 tumor progression. In this study, calcitriol and its analogs decreased the levels of VDR (Fig. 6A). ER $\alpha$ level was decreased during 4T1 progression, whereas ER $\beta$ level remained unchanged. Furthermore, calcitriol and its analogs decreased the levels of $\operatorname{ER} \beta$ on days 28 and 33 (Fig. 6A).

On day 21, a 2.5-fold increase in the ratio of E: $\mathrm{N}$-cadherin in tumor tissues of mice administered with calcitriol and its analogs was observed. In control tumors, this ratio was $\sim 1$. However, during tumor growth progression, the ability of calcitriol and its analogs to increase the ratio of E:N-cadherin was not observed (Fig. 6B).

In this study, we evaluated also the protein levels of transcription factors, namely, SNAI1 and PTEN. We found that their levels increased at the end of the experiment, whereas the levels of $\mathrm{NF \kappa B}$ and I $\mathrm{B}$ increased on day 28 and then rapidly decreased on day 33. Calcitriol and its analogs did not influence the levels of SNAI1, PTEN, and I $\kappa$ B, whereas on days 21 and 33, PRI-2191 and PRI-2205 caused increase in their levels. On day 28, all studied compounds decreased the levels of NFKB (Fig. 6C).

Increased levels of OPN and decreased levels of transforming growth factor $\beta$ (TGF $\beta$ ) in tumor tissue resulting from the treatment. The level of other proteins in tumor tissue was analyzed using enzyme-linked immunosorbent assay (ELISA). OPN levels in control tumors increased significantly during 4T1 tumor progression. Calcitriol and its analogs further increased its level. Both analogs elevated OPN level from day 14. Calcitriol showed some delay in this activity but significantly increased the levels of OPN from day 28 (Fig. 7A). TGF $\beta$ level in tumor tissue was significantly lowered by treatment using calcitriol and its analogs when compared to control (Fig. 7A).

Plasma OPN level measured on selected days of treatment was found to be increased by calcitriol and its analogs, however, opposite effect was seen in case of TGF $\beta$ levels in plasma. TGF $\beta$ was undetected in control tumor-bearing mice on days 21 and 33 of treatment, as well as in mice treated with calcitriol on day 21. PRI-2191 and PRI-2205 increased TGF $\beta$ level significantly. TGF $\beta$ level also increased in mice treated with calcitriol (from undetectable levels in control mice to $30 \mathrm{pg} / \mathrm{ml}$ in mice treated with calcitriol on day 33) (Fig. 7B).

Modulating effect of calcitriol and its analogs on collagen deposits in tumor and lung tissue. Histochemical analysis of tumors collected from control mice showed increased collagen deposits in tumor tissue during neoplastic progression as showed by Masson's trichrome staining. Treatment with calcitriol and its analogs on day 21 further increased the collagen deposits but the content was significantly low on day 28 (Fig. 8).

In most specimens of lungs, connective tissue (collagen fibers) was seen as a green staining of fibers around the bronchi and bronchioles, large vessels, and alveolar elements. During tumor progression, we found a slight decrease in staining intensity in control mice; however, PRI-2191 as PRI-2205 did not show a difference in staining intensity when compared with control mice. Calcitriol treatment seem to increase collagen fiber deposits in lungs, primarily on days 14 and 28 (from ++ to even ++++ ) (Table II).

Aortic remodeling during tumor progression and treatment with calcitriol and its analogs. During 4T1 tumor progression, we observed changes in the structure of aorta. When tumor became palpable (day 7), the number of cell layers of tunica media $(\mathrm{P}<0.05)$ and tunica adventitia decreased when compared to healthy (day 0) mice. Next, on day 14, the number of tunica media and tunica adventitia layers in control tumor-bearing mice increased significantly when compared to healthy (D0) and/or tumor-bearing mice on day 7. On day 21 , the number of tunica media and tunica adventitia layers did not change significantly. However, on the two last days of observation (days 28 and 33), the number of layers 
A
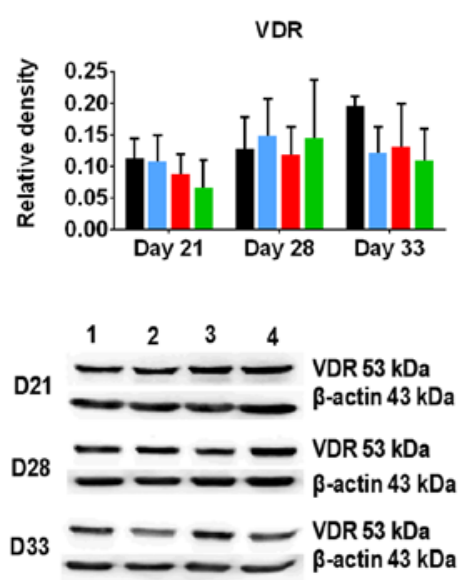

B

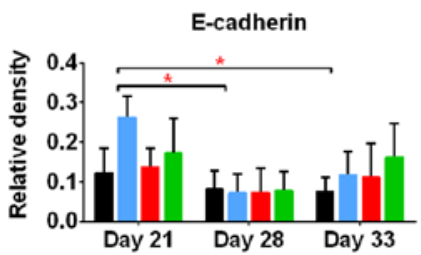

ERa
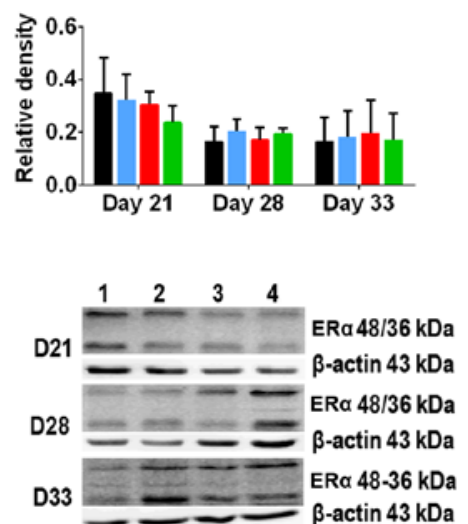

$\mathrm{N}$-cadherin

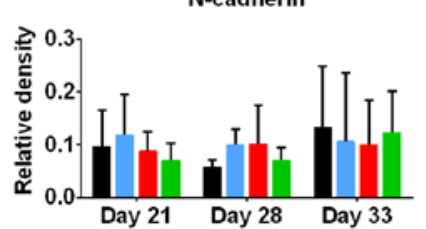

$E R B$
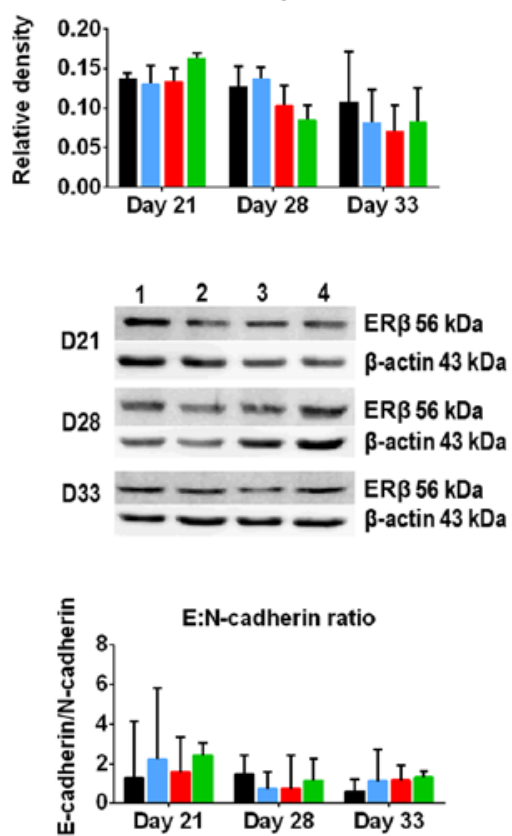

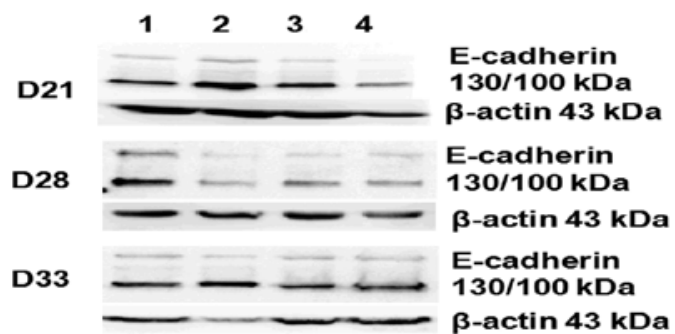

C

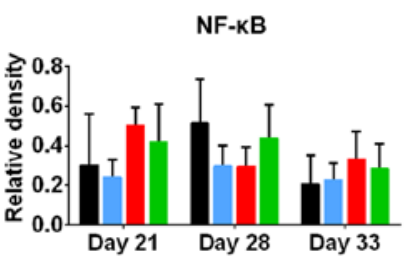

PTEN

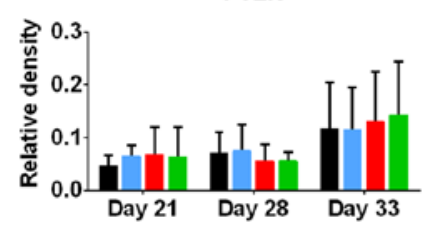

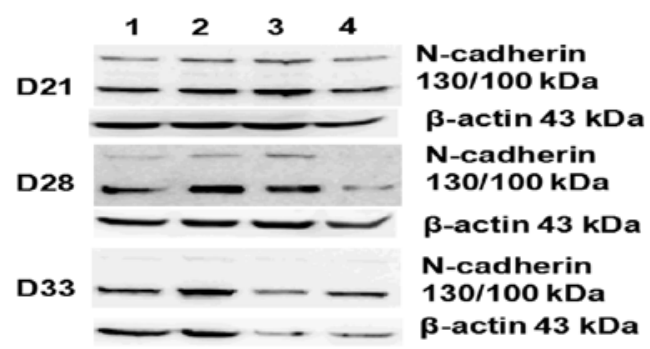

$\mathrm{IKBa}$
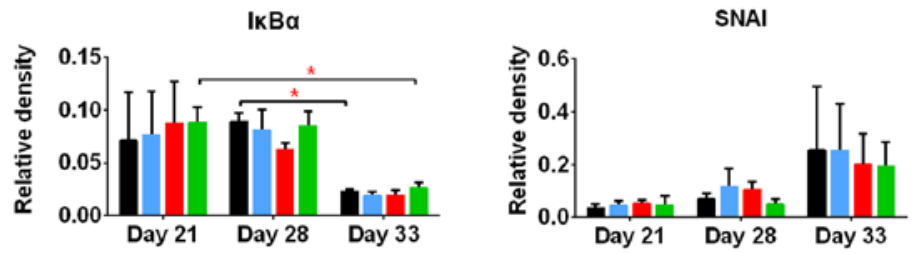
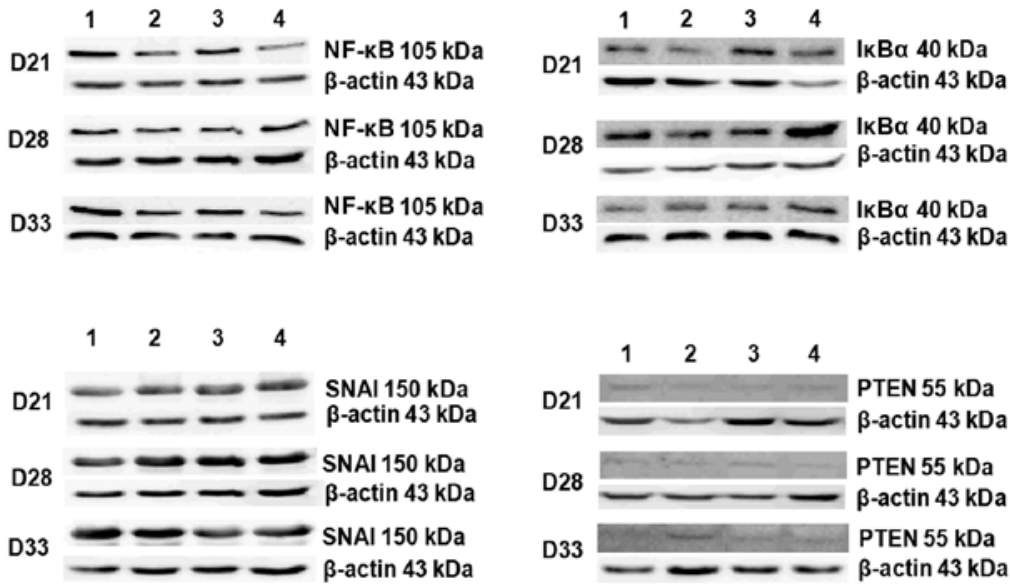

Figure 6. Selected proteins in 4T1 tumor tissue from mice treated with calcitriol or its analogs. Western blot analysis of (A) nuclear receptors; (B) epithelialmesenchymal transition markers; (C) transcription factors. Color bars, black, control animals; blue, calcitriol; red, PRI-2191; green, PRI-2205. Bands on the blot were determined as: 1, control animals; 2, calcitriol; 3, PRI-2191; 4, PRI-2205. Number of mice evaluated were 3-4 per group. Chemiluminescence was visualized using Image Station 4000MM PRO (Carestream). Densitometry analysis of the western blots was performed using Carestream MI Software 5.0.6.20 (Carestream Health). Data presentation: mean \pm standard deviation of protein tested to actin ratio and representative cropped blots. Statistical analysis: Holm-Sidak's multiple comparisons test; ${ }^{*} \mathrm{P}<0.05$ as indicated. 

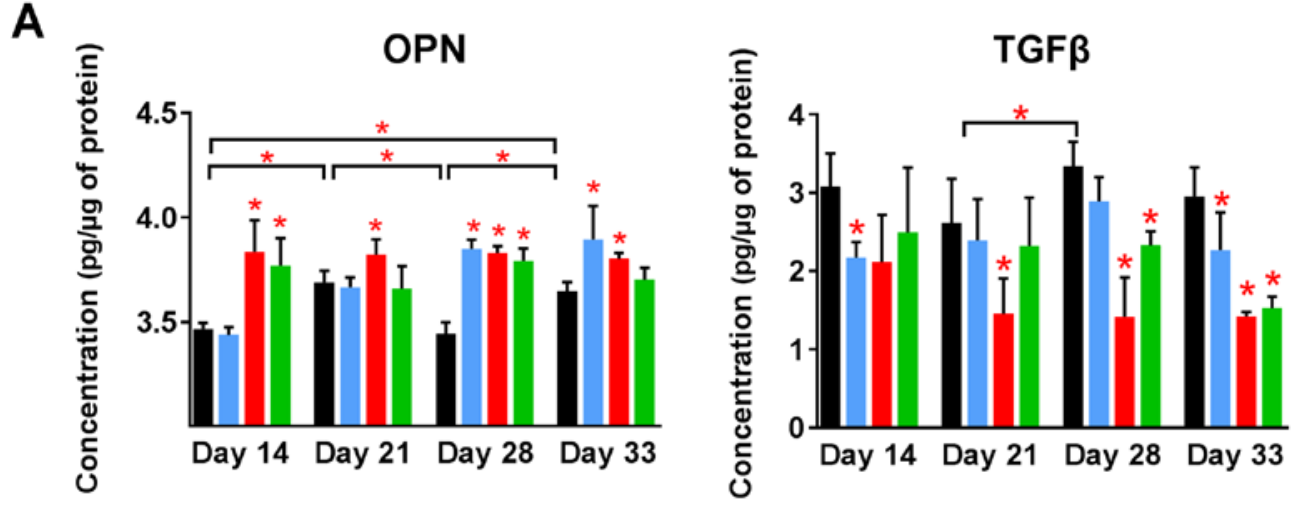

B

\section{OPN}
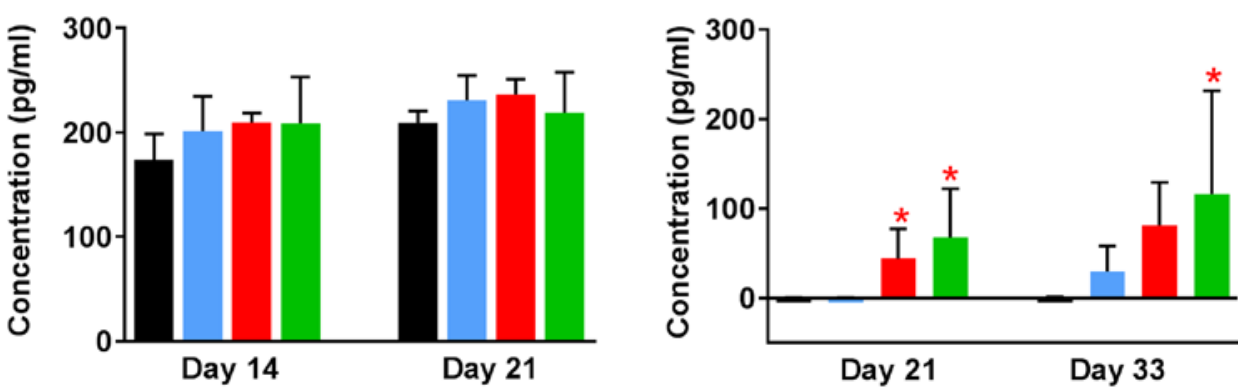

Figure 7. Osteopontin and transforming growth factor $\beta$ (TGF $\beta$ ) level in tumor tissue and in plasma of mice. ELISA proteins levels analyzed in (A) tumor tissue and (B) plasma. Color bars, black, control animals; blue, calcitriol; red, PRI-2191; green, PRI-2205. Number of mice evaluated were 4-7 per group. Data are presented as mean \pm standard deviation. Statistical analysis: (A) Tukey's multiple comparison test; (B) Dunnett's multiple comparison test. "P<0.05 as compared to control animals on the relevant day of treatment or as indicated.
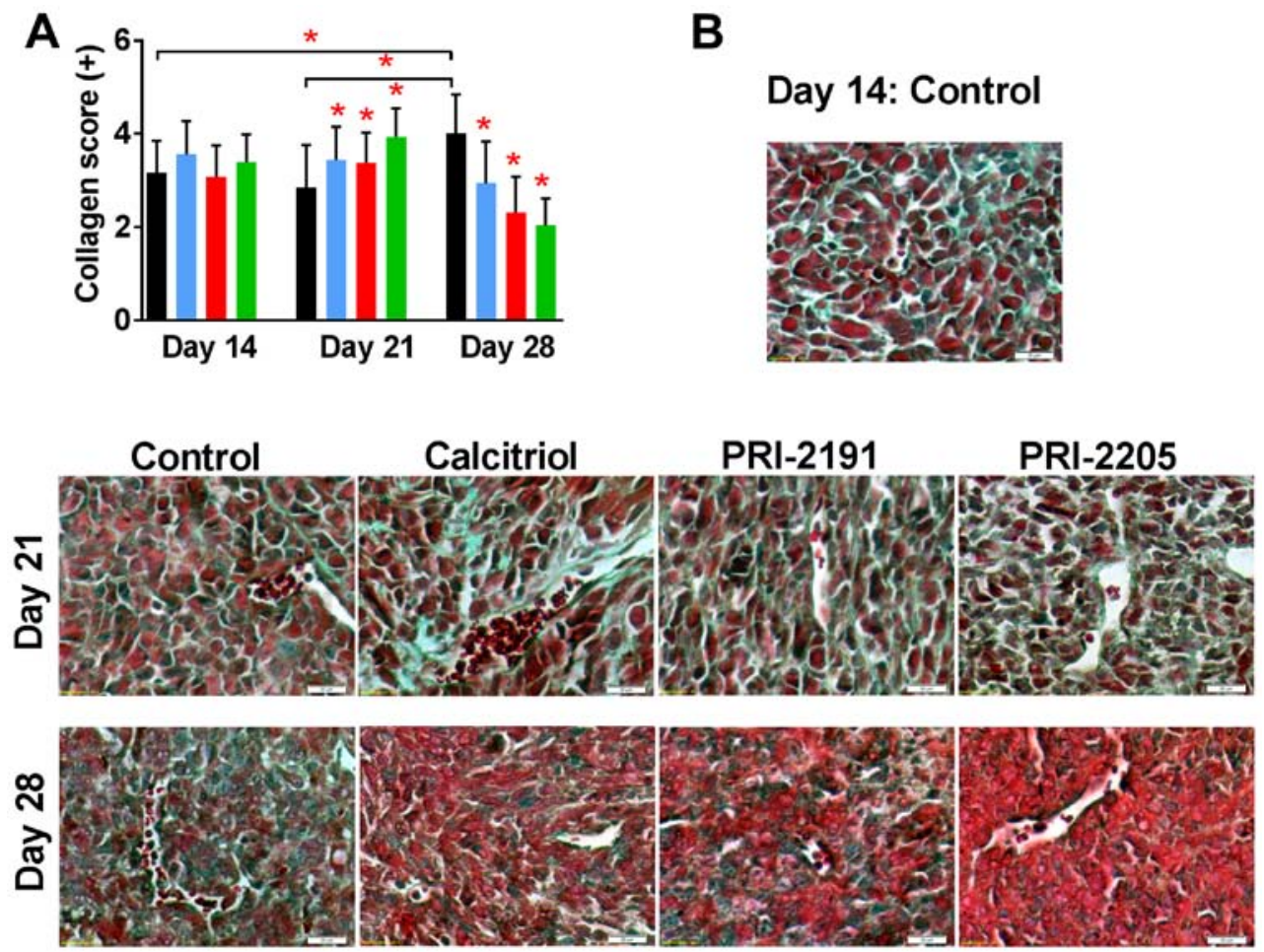

Figure 8. Collagen staining in tumor tissue from mice treated with calcitriol or its analogs. Color bars, black, control animals; blue, calcitriol; red, PRI-2191; green, PRI-2205. Number of mice evaluated were 6 per group. (A) Data are presented as mean \pm standard deviation. Statistical analysis: Kruskal-Wallis multiple comparison test. ${ }^{*} \mathrm{P}<0.05$ as compared to control animals on the relevant day of treatment or as indicated. (B) Representative photographs. Magnification, $\mathrm{x} 40$; scale bar, $20 \mu \mathrm{m}$. The sections were immersed respectively in azoploxine solution for cytoplasm dyeing, Tungstophosphoric acid orange $\mathrm{G}$ solution for erythrocytes staining, and Light green SF solution for collagen and connective tissue visualization. Semiquantitative evaluation of collagen was based on the presence of single collagen fibers around single cells (+), single collagen fibers around all cells (++), the medium (+++), significant (++++) and very abundant (+++++) collagen deposits in sight. 

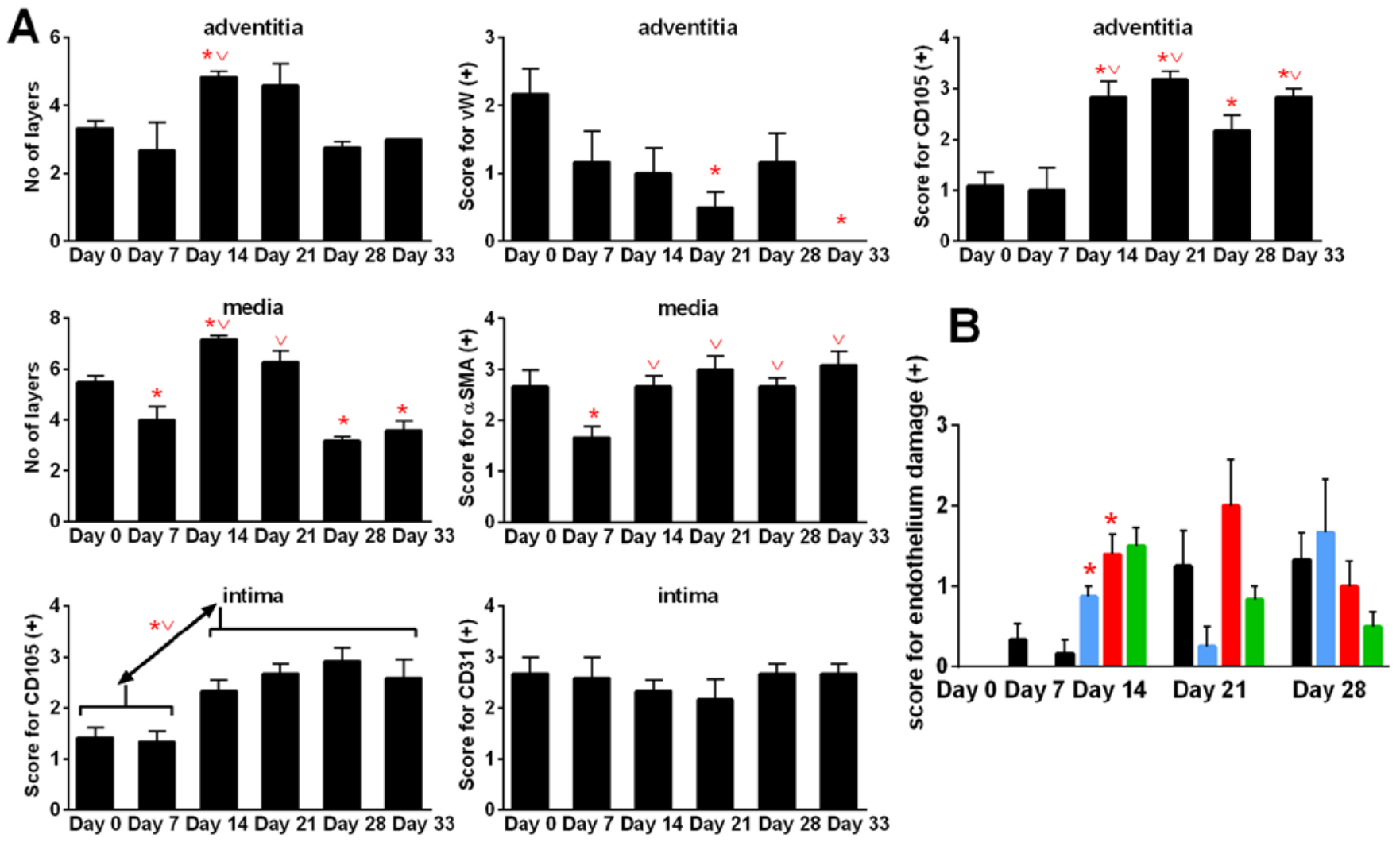

Figure 9. Kinetics of aorta remodeling in control mice during tumor progression and score for endothelium damage during treatment with calcitriol or its analogs. (A) Kinetic of aorta remodeling in control mice. (B) Score for endothelium damage. Color bars, black, control animals; blue, calcitriol; red, PRI-2191; green, PRI-2205. Number of mice evaluated were six per group. Data are presented as mean \pm standard deviation. Statistical analysis: (A) Mann-Whitney U test. ${ }^{*} \mathrm{P}<0.05$ as compared to $\mathrm{D} 0,{ }^{\mathrm{v}} \mathrm{P}<0.05$ as compared to $\mathrm{D} 7$. (B) Kruskal-Wallis multiple comparisons test. ${ }^{*} \mathrm{P}<0.05$ as compared to control on day 14 .

of tunica adventitia and tunica media decreased. In case of tunica media, the decrease in cell layers was greater and statistically significant (days 28 and 33) than that of healthy mice (day 0). The $\alpha$-smooth muscle actin ( $\alpha$ SMA) staining decreased at the beginning of tumor growth (day 7) and then increased to the values similar to the healthy mice. Stained with von Willebrand factor (vWF), vasa vasorum endothelial cells decreased during 4T1 tumor progression and were not detectable on day 33. However, staining with anti-endoglin (CD105) antibody showed increased intensity on day 14 when compared to healthy (day 0 ) and tumor-bearing mice on day $7(\mathrm{P}<0.05)$. CD31 antigen of intima endothelial cells was unchanged during tumor growth in control tumor-bearing mice; however, endoglin significantly increased starting from day 7 (Fig. 9A).

Calcitriol and PRI-2205 decreased the number of tunica media layers on day 14 and PRI-2205 on day $21(\mathrm{P}<0.05)$. In the advanced stages of tumor development (days 28 and 33), both calcitriol and PRI-2191 increased the CD105 score. In mice treated with PRI-2205, the number of tunica media layers remained on the lower level similar to tumor-bearing mice on day 7. The number of tunica adventitia layers was affected by the tested compounds only in the earlier stages of tumor development. PRI-2205 significantly decreased the number of layers on days 14 and 21 . The tendency to decrease the thickness of tunica adventitia of aorta was also observed in PRI-2191-treated mice. PRI-2205 tended to decrease CD31 (day 21) and CD105 intima-positive cells (days 28 and 33 with an exception on day 14, where significant increase was observed). A similar tendency was observed according to CD105 and vWF-positive cells in tunica adventitia. However, calcitriol and PRI-2191 increased the number of vWF stained adventitia cells. During the course of treatment, calcitriol increased the staining intensity of CD105 intima (days 14 and 33: $\mathrm{P}<0.05$ ). PRI-2191 on day 14 significantly decreased CD105 staining of intima cells (Fig. 10).

The damage to endothelium observed in hematoxylin and eosin-stained aorta slices in general respond to changes in intima endoglin (CD105) staining (Fig. 9B). During this examination, the aortas showed no change $(0)$ or a number of changes observed in terms of damage to the individual endothelial cells (marked + ) or lying next to each other in a small space in a number of such locations $(++)$, or endothelial cells invaded by erythrocytes and/or dissection (+++). Calcitriol and its analogs increased endothelium damage on day 14 (Fig. 9B).

Calcitriol and its analogs exert different action against metastatic $4 T 1$ cells and its non-metastatic counterparts $67 N R$ in vitro. This part of the study was performed to evaluate the direct influence of calcitriol and its analogs on 4T1 metastatic cells in vitro and compare the results with non-metastatic subline 67NR.

Calcitriol and its analogs inhibited proliferation of non-metastatic $67 \mathrm{NR}$ cells but did not influence 4T1 cell proliferation significantly (Fig. 11A and Table V). We used 

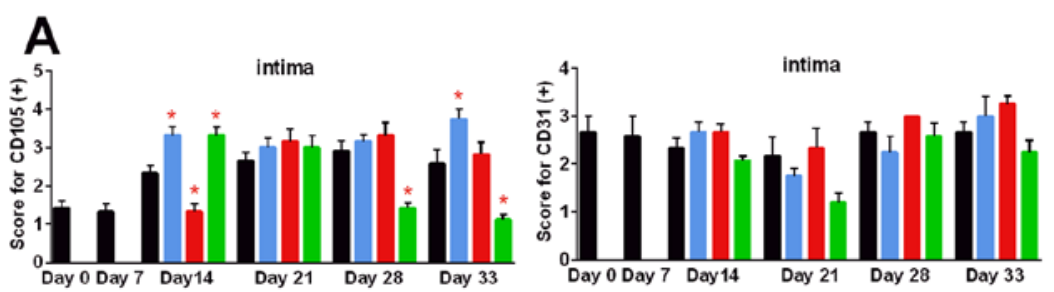

D

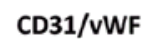

CD105/ $\alpha$ SMA

B
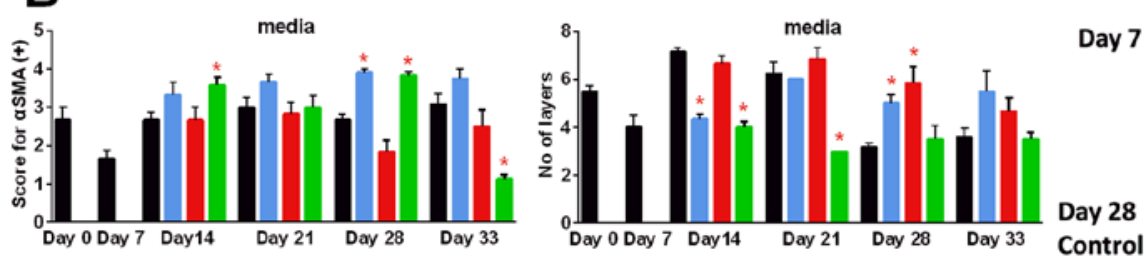

Day 0
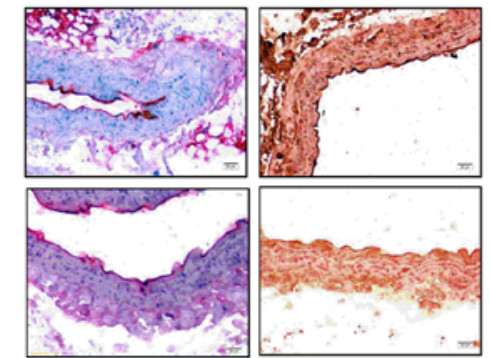

C
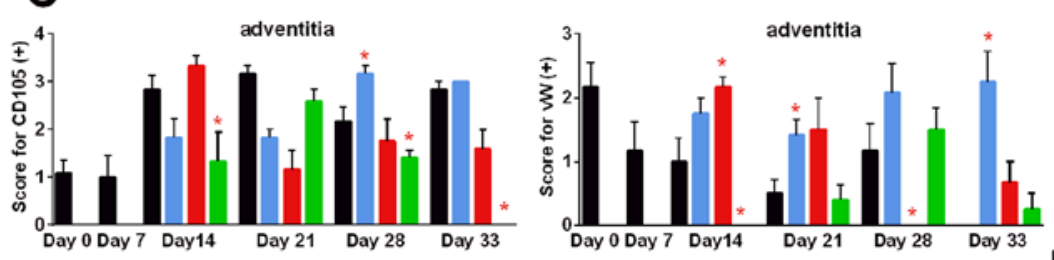

Control
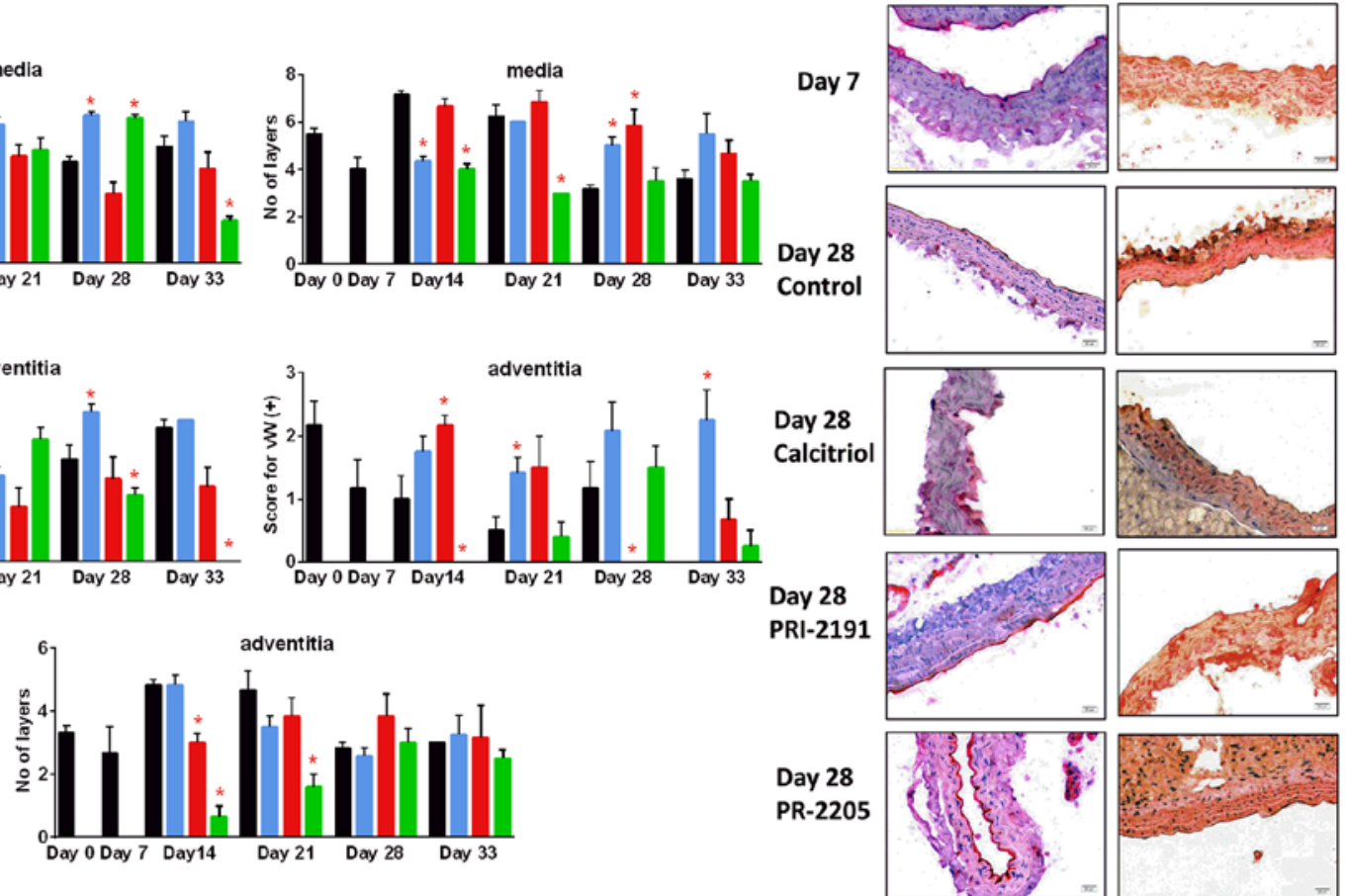

Figure 10. Kinetics of aorta remodeling during tumor progression and treatment with calcitriol or its analogs. (A) Intima CD31 and CD105 expression. (B) Media thickness and the $\alpha$-smooth muscle actin ( $\alpha$ SMA) staining. (C) Adventitia thickness and von Willebrand factor (vWF), CD105 expression. (D) Representative photographs of aortic wall from selected groups of mice. Color bars, black, control animals; blue, calcitriol; red, PRI-2191; green, PRI-2205. Number of mice evaluated were 6 per group. Data are presented as mean \pm standard deviation. Statistical analysis: Mann-Whitney U test. "P<0.05 as compared to control animals on the relevant day of treatment. Magnification, x20; scale bar, $20 \mu \mathrm{m}$.

cisplatin, doxorubicin, docetaxel, 5-fluorouracil, tamoxifen, and camptothecin as the control anticancer drugs, to show the sensitivity of $4 \mathrm{~T} 1$ cells for in vitro anticancer drugs in the same experimental condition as used for calcitriol and its analogs. Similar antiproliferative activities of most anticancer drugs were observed for both cell sublines. However, 4T1 cells revealed less sensitivity to tamoxifen and 5-fluorouracil when compared to 67NR cells (Table V).

According to our results, 67NR cells secreted OPN into the culture medium and it increased significantly during the time of incubation. However, in case of 4T1 cells, OPN secretion increased up to $48 \mathrm{~h}$ of incubation and the level was maintained up to $72 \mathrm{~h}$ (Fig. 11B). Furthermore, $4 \mathrm{~T} 1$ cells secreted significantly higher levels of OPN than that of 67NR cells, and calcitriol and its analogs $(100 \mathrm{nM})$ did not alter its levels (Fig. 11B). Starting from $48 \mathrm{~h}$ of incubation, calcitriol and both analogs significantly increased the secretion of OPN by $67 \mathrm{NR}$ cells (Fig. 11B, right graph). After $72 \mathrm{~h}$ of incubation with $100 \mathrm{nM}$ calcitriol and its analogs, the levels of $\mathrm{E}$ - and $\mathrm{N}$-cadherin, $\beta$-catenin, VDR, $\mathrm{RXR} \alpha$, and ER $\alpha$ were measured. The results are presented in Fig. 12. Calcitriol and its analogs did not affect the expression of aforementioned proteins in 4T1 cells. The results also show that $4 \mathrm{~T} 1$ and $67 \mathrm{NR}$ cells expressed similar
Table V. Antiproliferative activity of tested compounds and positive controls against mammary gland cancer sublines: metastatic 4T1 and non-metastatic 67NR cells.

\begin{tabular}{lcc}
\hline \multirow{2}{*}{ Compound } & 4T1 cells & 67NR cells \\
\cline { 2 - 3 } & \multicolumn{2}{c}{$\mathrm{IC}_{50}(\mathrm{nM})$} \\
\hline Calcitriol & - & $25.04 \pm 9.30$ \\
PRI-2191 & - & $23.52 \pm 5.93$ \\
PRI-2205 & \multicolumn{2}{c}{$230.73 \pm 12.14$} \\
\hline \multicolumn{2}{c}{$\mathrm{IC}_{50}(\mu \mathrm{g} / \mathrm{ml})$} \\
\hline Cisplatin & $0.38 \pm 0.090$ & $0.30 \pm 0.050$ \\
Doxorubicin & $0.04 \pm 0.002$ & $0.05 \pm 0.012$ \\
Docetaxel & $0.01 \pm 0.000$ & $1.20 \pm 0.990$ \\
Camptothecin & $0.03 \pm 0.003$ & $0.04 \pm 0.036$ \\
5-fluorouracil & $0.46 \pm 0.044$ & $0.11 \pm 0.079^{\mathrm{a}}$ \\
Tamoxifen & $3.05 \pm 0.237$ & $1.46 \pm 0.164^{\mathrm{a}}$ \\
\hline
\end{tabular}

The inhibitory concentration $50 \%\left(\mathrm{IC}_{50}\right)$ value is defined as the concentration of a compound that corresponds to a $50 \%$ growth inhibition. Experiments were repeated three times in triplicates. Data presented as mean \pm standard deviation. ${ }^{\mathrm{a}} \mathrm{P}<0.05$, Student's t-test. 


\section{A}
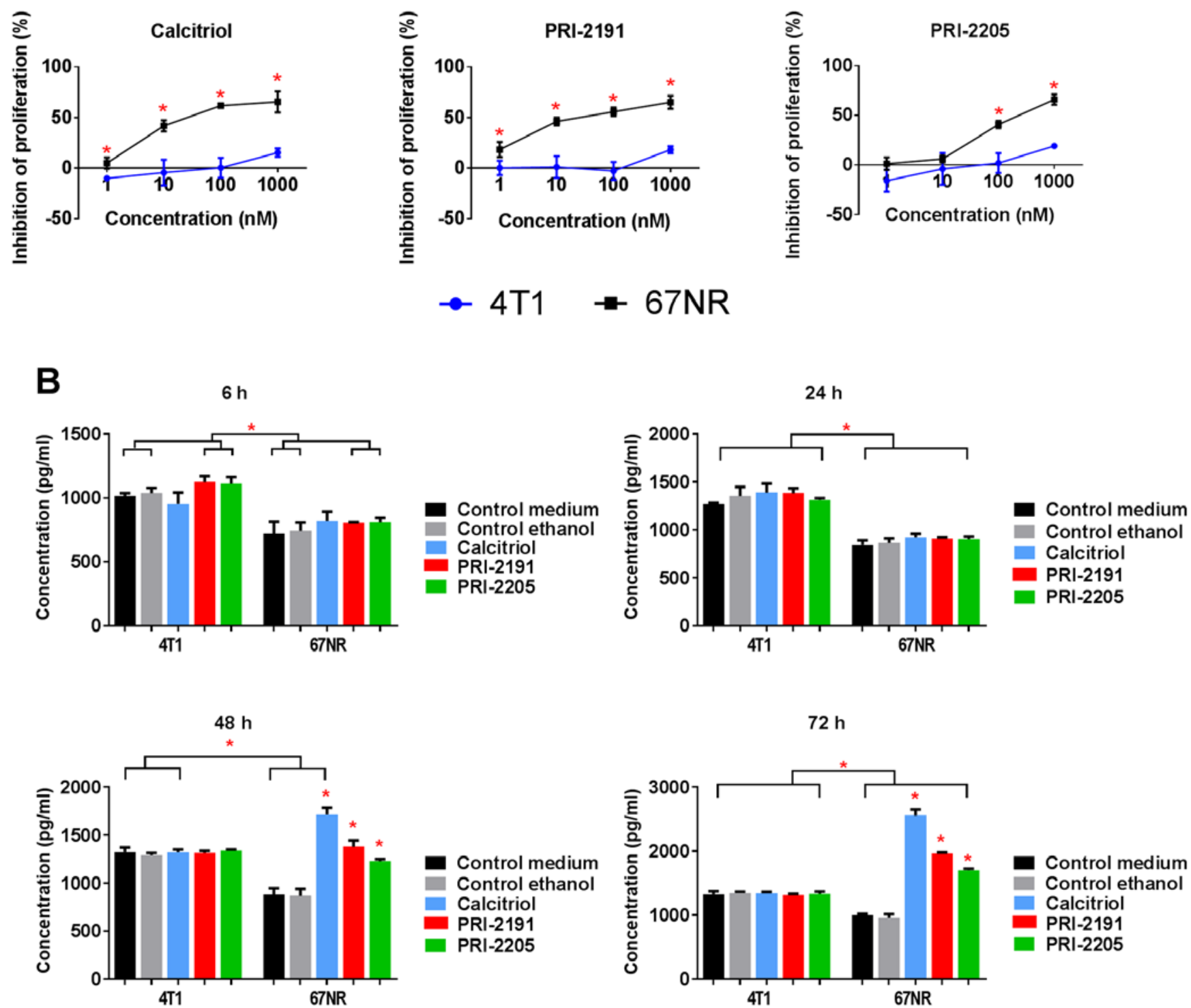

Figure 11. The in vitro proliferation inhibition and the osteopontin secretion to the culture media of 67NR and 4T1 cells after treatment with calcitriol or its analogs. (A) The proliferation inhibition curves. (B) Osteopontin secretion to the culture media at various time points after incubation with calcitriol or its analogs. Color bars, black, control medium; gray, ethanol control; blue, calcitriol; red, PRI-2191; green, PRI-2205. Experiments were repeated thrice at least in triplicates. Data are presented as mean \pm standard deviation. Statistical analysis: (A) Student's t-test, "P<0.05 as compared to 4T1; (B) Sidak's multiple comparisons test, ${ }^{*} \mathrm{P}<0.05$ as compared to both controls or as indicated.

level of $\mathrm{N}$-cadherin, and this expression was increased significantly in $67 \mathrm{NR}$ cells by calcitriol or its analogs. The 67NR cells did not express E-cadherin. The expression of $\beta$-catenin, and VDR proteins were higher in 4T1 than in 67NR cells. Calcitriol increases significantly the expression of $\beta$-catenin in 67NR cells. On the other hand, the expression of RXR $\alpha$ and ER $\alpha$ was significantly lower in 4T1 than 67NR cells. Calcitriol (ER $\alpha)$ or calcitriol and its analogs $(\mathrm{RXR} \alpha)$ increased the expression of these proteins significantly only in $67 \mathrm{NR}$ cells. The expression of vitamin D metabolizing enzymes namely, CYP27B1 and CYP24A1 were unchanged in 4T1 cells after treatment with the tested compounds. However, in case of 67NR cells, the expression of both the enzymes increased significantly after incubation with calcitriol or its analogs (Fig. 12).

\section{Discussion}

In this study, we conducted experiments on the mouse 4T1 mammary gland cancer cells transplanted into the mammary fat pad of the immune-competent BALB/c female mice. This research model is commonly used for late-stage (IV) basal-like human breast cancer model because similar to that observed in humans 4T1 cells spontaneously metastasize via hematogenous route into lungs, brain, liver or bones (34). Moreover, 4T1 tumor progression is accompanied by the activation of the platelets (36) and of host immune cells (37), thus it provides a model for the studies on a broad range of metastatic features.

Banka et al (38) showed that the expression of endogenous ER $\alpha$ was not detected in $4 \mathrm{~T} 1$ breast carcinoma cells. 

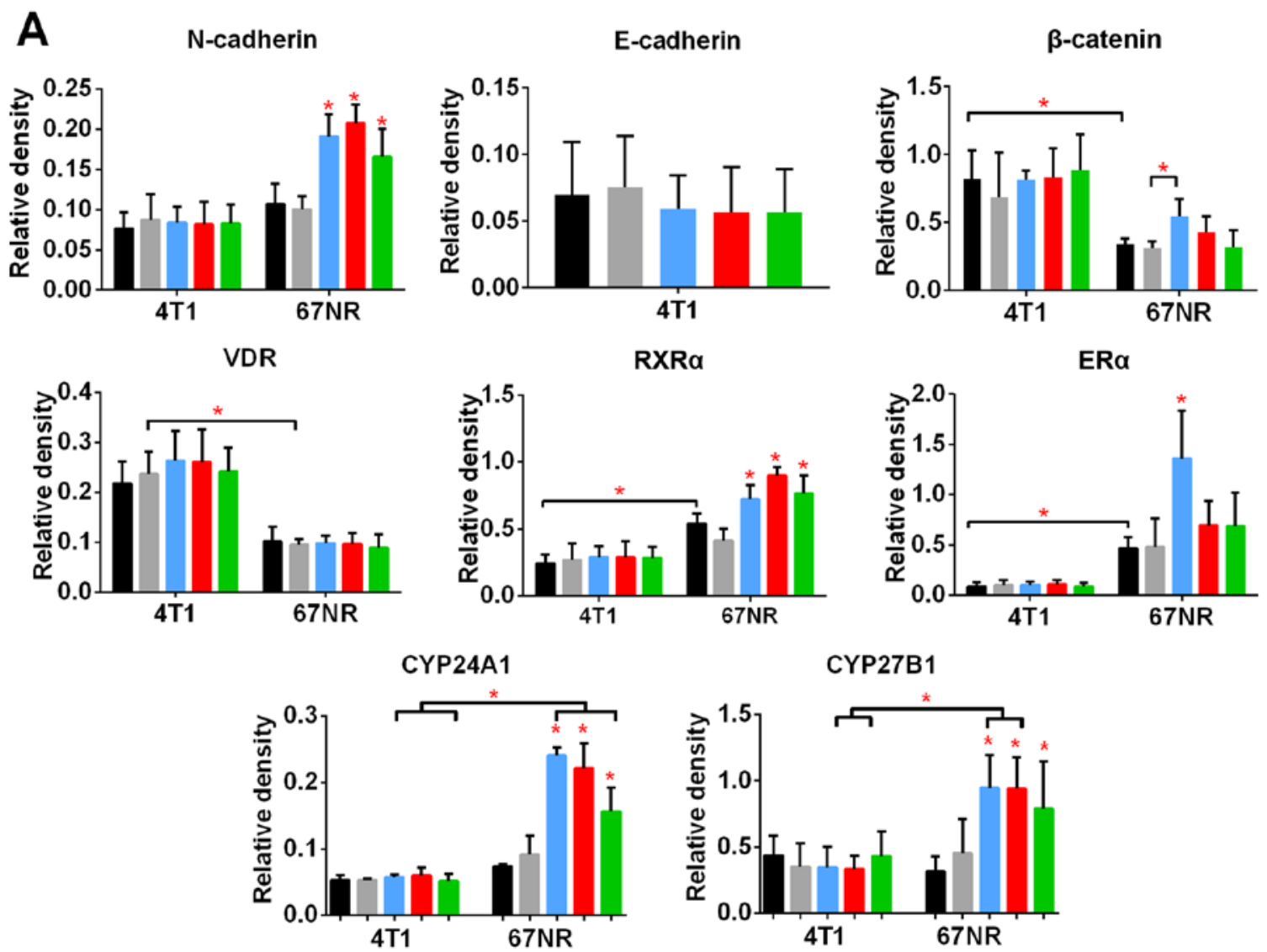

B

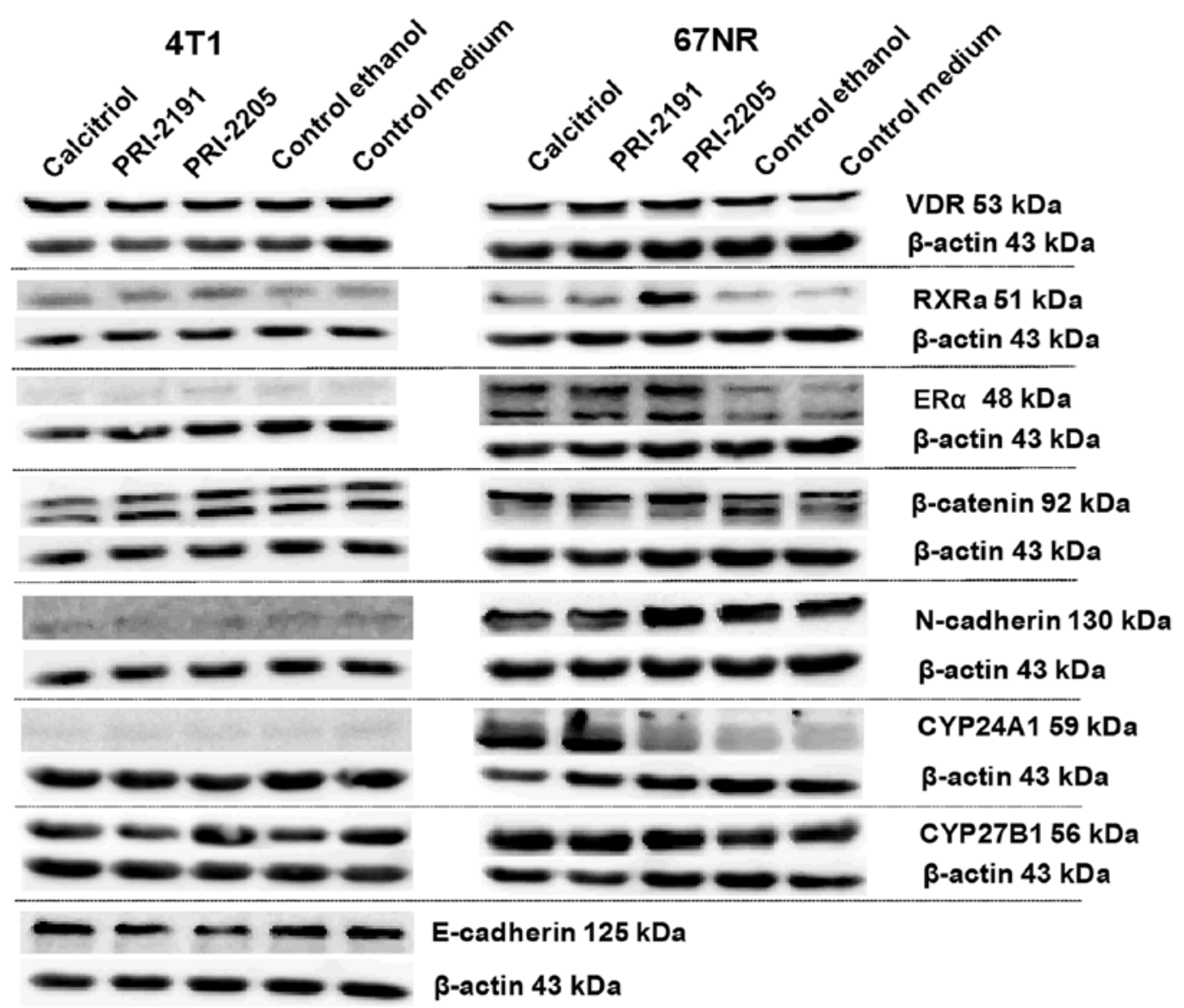

Figure 12. Western blot analysis of the expression of selected proteins in 4T1 and 67NR cells cultured in vitro. (A) Western blot analysis of selected protein expression. (B) Representative blots. Color bars, black, control medium; gray, ethanol control; blue, calcitriol; red, PRI-2191; green, PRI-2205. Experiments were repeated thrice. Results are expressed as mean \pm standard deviation of protein tested to actin ratio and representative cropped blots. Statistical analysis: Dunnett's multiple comparisons test. ${ }^{*} \mathrm{P}<0.05$ as compared to both controls or as indicated. 
Calcitriol and its analogs activities

in 4T1 mammary gland cancer bearing mice

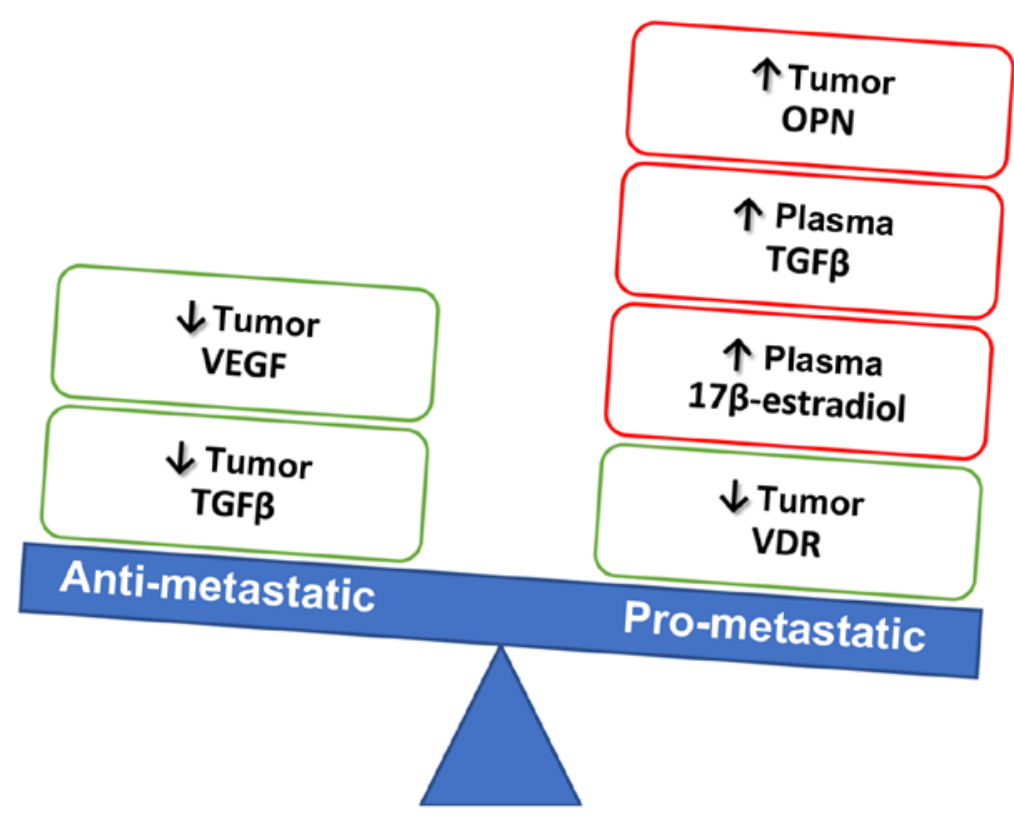

Figure 13. Proposed mechanisms leading to lung metastasis enhancement by calcitriol and its analogs in 4T1 mammary gland cancer model.

Moreover, estrogens did not induce proliferation or Erk1/2 phosphorylation of 4T1 cells in vitro. However, estrogens can stimulate metastasis of such ER-negative tumors $(39,40)$. Our study, similarly to other research (41), revealed that 4T1 tumors express ER $\alpha$ and $\beta$, and according to our results, the level of ER $\alpha$ decreased throughout tumor progression, whereas the level of ER $\beta$ remained unchanged. In cell culture studies, 4T1 cells did not show sensitivity to antiproliferative activity of calcitriol or its analogs (PRI-2191 and PRI-2205) as presented in this study and previously (27). Moreover, the in vivo experiment conducted on mice bearing 4T1 tumors transplanted orthotopically have shown that PRI-2205 did not affect the growth of primary tumors significantly, but enhanced the metastatic potential of 4T1 cells when used alone. However, when combined with cyclophosphamide, PRI-2205 improved its effectiveness (27). Now, in two independent experiments, we have shown that calcitriol and its analogs (PRI-2191 and PRI-2205) did not influence the primary tumor growth but increased the metastatic potential of 4T1 cells. Although calcitriol was used in lower dose $(0.5 \mu \mathrm{g} / \mathrm{kg})$ than other analogs, its toxicity was visible and manifested as a reduction in body weight and a rise in serum calcium level.

The significance of OPN (encoded by the Sppl) as a key molecule in the progression and metastasis of $4 \mathrm{~T} 1$ cancer cells has been previously described $(42,43)$. Moreover, OPN is correlated with advanced stage and metastasis of breast (44) and other (45-47) tumors and with resistance to chemotherapy (48). OPN revealed its activity using a number of receptors, including the integrins $\alpha_{\mathrm{v}} \beta_{1}, \beta_{3}$, or $\beta_{5}$ and $\alpha_{4}, \alpha_{5}, \alpha_{8}$, or $\alpha_{9} \beta_{1}$, and it may also be a ligand for CD44 receptor (49-52). Directly through activation of these receptors or indirectly, OPN acts as a chemotactic agent for macrophages and stimulates proinflammatory activity of macrophages, fibroblasts, natural killer (NK) cells, and endothelial cells, thereby inducing angiogenesis and collagen deposits $(50,53,54)$. Furthermore, vitamin D responsive element (VDRE) in the promoter region of Sppl has been reported (55), and the enhancement of OPN levels was found in various cells treated with calcitriol and its analogs (55-61).

In this study, in control tumor-bearing mice, the tumor OPN level increased, but tumor VEGF level decreased with progression of neoplasia. This is inconsistent with the data suggesting that exogenous, as well as tumor-derived OPN augments both VEGF mRNA and VEGF protein levels in breast cancer $(54,62)$. However, in our tumor model, similar to other studies $(63,64)$, the expression of mesenchymal markers such as SNAI1 and N-cadherin increased in subsequent days of tumor growth, whereas the expression of E-cadherin, typical for epithelial phenotype, decreased.

In the in vitro studies by $\mathrm{Xu}$ et al on rat mammary gland cancer cells, OPN levels were found to be increased by calcitriol and its analogs. Nevertheless, suppression of $\beta$-catenin and upregulation of E-cadherin signaling was also noted, as authors suggest this can neutralize such adverse effect of calcitriol inducing OPN secretion (56). In our research model, calcitriol and its analogs did not influence the secretion of OPN into the culture medium of 4T1 cells and did not influence the levels of $\beta$-catenin, E-cadherin or $\mathrm{N}$-cadherin in vitro. $67 \mathrm{NR}$ cell subline has been described as less invasive (65) and despite a lower level of VDR than in 4T1 cells, 67NR cells are sensitive to the induction of OPN secretion, as well as, for example, upregulation of $\mathrm{N}$-cadherin expression 
by calcitriol and its analogs (our studies). Moreover, in this study, non-treated 67NR cells secreted lower levels of OPN into the culture medium than that of 4T1 cells as described in the literature related to a less invasive phenotype (42).

However, in in vivo experiments, we observed induction of OPN in 4T1 tumor tissue after treatment with calcitriol and its analogs. Therefore, in our in vivo $4 \mathrm{~T} 1$ tumor model, OPN induction by calcitriol and its analogs is not cancer cell-derived but rather host-cell derived. This is also supported by the fact that only a weak tendency to upregulate the ratio of $\mathrm{E}: \mathrm{N}$ cadherins at the beginning and at the end of experiment by calcitriol and its analogs were observed, despite decreased tumor TGF $\beta$ [known cytokine driving epithelial to mesenchymal transition (66)] level by the treatment used.

With the increase in OPN levels in tumor tissue, after treatment with vitamin D compounds, we observed a decrease in tumor VEGF level. In parallel, the tumor blood perfusion was improved by all compounds, which could mean tumor vasculature normalization via VEGF depletion $(67,68)$. However, in this study, we found an increased activation of aortal endothelium (increase of endoglin staining) during tumor growth and remodeling of tunica media and adventitia. Calcitriol further increased the activation of endothelial cells as measured by endoglin expression (PRI-2191 showed similar trend, but PRI-2205 was the opposite at the end of the experiment) and increased vascularization in tunica adventitia (increased vWF staining). These changes in the activity of endothelial cells outside the tumor tissue correlated with plasma $17 \beta$-estrogen and TGF $\beta$ level. OPN is known for its ability to enhance the migration, homing, and differentiation of endothelial progenitor cells (EPCs) (69). According to a study, the activity of estrogens as accelerators of the endothelial repair requires OPN, both for bone marrow-derived cell recruitment and for endothelial cell migration and proliferation (70). Apart from the localized action of OPN in tumor tissue, it has been documented that tumor or host-produced OPN influences metastatic niche establishment significantly. Sangaletti et al have shown that the host-derived OPN, primarily from myeloid cells, form the immunosuppressive environment in metastatic niche in the lungs facilitating lung metastatic foci formation (43). Moreover, low concentrations of TGF $\beta$ (decreased tumor concentration of TGF $\beta$ was observed in our studies) can promote blood vessel formation. However, higher amounts can be antiangiogenic (71-73). TGF $\beta$ also revealed direct effects on endothelial cell growth and migration and also on the regulation of the activation state of the endothelium $(74,75)$. Therefore, normalized tumor blood vasculature with activated endothelium (as we showed in aorta sections) driven by tumor OPN, plasma estrogens, and TGF $\beta$ overexpression may lead to the induction of metastasis by calcitriol and its analogs.

TGF $\beta$ is a cytokine that acts as a tumor suppressor when directed to normal cells, whereas it acts as a tumor promoting factor when directed to cancer cells. The action of TGF $\beta$ on tumor cells can be direct, inducing invasive phenotype in these cells or indirect conducing tumor-permissive microenvironment (76). Stromal collagenous extracellular matrix, primarily produced by cancer-associated fibroblasts (CAFs), is associated with increased risk of metastasis; TGF $\beta$ produced by cancer cells and/or CAFs promotes its accumulation. Inhibition of fibrosis using TGF $\beta$ antagonist can support inhi- bition of tumor growth and metastasis (77). In addition, OPN is identified as molecule reprogramming fibroblasts to tumorpromoting, proinflammatory CAFs in breast tumor tissue (78). Furthermore, Weber et al proved that the transformation of mesenchymal stem cells to CAFs initialized by OPN is mediated via TGF $\beta$ pathway (79). This OPN-TGF $\beta$ relationship may explain the initial increase in collagen deposits in tumor tissue by tested compounds, probably stimulated by OPN activity with enough TGF $\beta$ level in tumor microenvironment contributing to increased metastasis observed in our studies. In more advanced cancer stage, tumor collagen deposits were decreased by vitamin D compound treatments probably via tumor TGF $\beta$ downregulation, despite the high levels of OPN. In addition, in vitro experiments of others showed that calcitriol and its analogs induce TGF $\beta$ mRNA and protein level in an ER-negative breast cancer cell line (80). However, calcitriol is known to repress collagen synthesis in a number of cells by the interference with the TGF $\beta$-activated pathway (reviewed in refs. 81,82). Therefore, this potentially positive tumor TGF $\beta$ downregulating activity of calcitriol and its analogs is probably predominated by the impact of OPN on CAFs. It led to collagen prometastatic action in earlier steps of tumor progression as well as increased plasma TGF $\beta$ levels in later stages. Elevated TGF $\beta$ plasma level is proposed as a marker of metastatic breast cancer with poor prognosis (83). Moreover, TGF $\beta$ is known to modulate regulatory T-cell (Treg) differentiation, which suppress antitumor $\mathrm{T}$ cell response (84). TGF $\beta$ also promotes the differentiation of tumor-promoting tumor-associated macrophages (M2), and tumor-associated neutrophils (N2) $(85,86)$. Wculek and Malanchi have also shown that in the mouse 4T1 mammary gland cancer model neutrophils in lung premetastatic niche support metastatic potential of cancer cells (87). In the same tumor model, the co-injection of M2 macrophages into the mammary fat pads of mice increased solid tumor growth and lung metastasis (88).

Similarly, the tendency to decrease nuclear factor-kB (NFאB) transcription factor, observed in this study on day 28 and an increase observed on day 33, probably is the result of action of calcitriol and its analogs on tumor-associated cells as CAFs or immune cells. Adams and Teegarden have shown that calcitriol inhibits apoptosis in C3H10T1/2 murine fibroblast cells through activation of $\mathrm{NF \kappa B}$ (89), whereas Cohen-Lahav et al have demonstrated that calcitriol inhibits the expression of tumor necrosis factor $\alpha$ (TNF $\alpha)$ in macrophages by increasing inhibitory protein IkB $\alpha$ and decreasing the activity of NFKB (90). Therefore, further studies on isolated tumor macrophages and fibroblasts are highly warranted in order to explain the impact of calcitriol and its analogs on NFkB transcription factor in tumor tissue.

In this study, we observed that during the 4T1 tumor progression, VDR levels increased and the highest level was observed on the last day of the experiment. Calcitriol and its analogs tend to decrease the level of VDR, especially at the end of the experiment. Williams et al showed that VDR knockdown in 168FARN tumor cells as well as dietinduced vitamin D deficiency accelerates tumor growth and metastasis. Moreover, VDR signaling suppressed inhibitor of DNA binding 1 gene (Idl) expression, and there was a negative association between circulating 25(OH)D levels and the expression of ID1 in primary tumors from breast 
cancer patients (91). The 168FARN cell line is derived from the same single mouse mammary tumor as $4 \mathrm{~T} 1$ or $67 \mathrm{NR}$ used in our studies and is non-metastatic (92). Because Williams et al concluded that the loss of VDR signaling is sufficient to convert the cells from non-metastatic to metastatic state (91), therefore, even slight decrease in VDR level after treatment with calcitriol or its analogs observed in our studies could contribute to the observed elevation of metastases in the lungs of mice. However, this decrease may concern tumor stromal cells and therefore does not appear to be correlated with $I d l$ expression, which remained almost unchanged in tumor tissue taken from mice treated with tested compounds in our PCR screening studies. Moreover, as we have shown in in vitro studies, 4T1 cells expressed greater amount of VDR than 67NR cells, the isogenic cell line derived from the same primary breast cancer but nonmetastatic $(92,93)$. However, VDR in 4T1 cell line does not respond to calcitriol or its analogs in vitro. This is emphasized by lack of changes even in the expression of vitamin D metabolizing enzymes such as CYP27B1 (which converts the precursor form of vitamin D metabolite, 25-OH-D, to the active metabolite, calcitriol) and CYP24A1 (which degrades calcitriol). Expression of these enzymes is directly regulated by calcitriol $(94,95)$. The insensitivity of cancer cells to the action of calcitriol or its analogs despite the presence of VDR can be explained by various epigenetic mechanisms such as promoter hypermethylation (96), elevated nuclear receptor co-repressor 1 (NCoR1) (97), silencing mediator of retinoic acid and thyroid hormone receptors (SMRT) (98), and histone deacetylase (HDAC) enzymes (97). Moreover, Zhi et al have shown that the tyrosine phosphatase PTPH1 stimulates breast cancer growth through regulating VDR expression/localization. PTPH1 binds to VDR and increases its cytoplasmic accumulation leading to their stabilization. Deficiency of a nuclear located VDR abolishes the growth-inhibitory activity of the receptor (99). Nevertheless, further studies are needed to determine whether this mechanism is responsible for the insensitivity of $4 \mathrm{~T} 1$ cells to calcitriol despite the presence of the receptor and how these mechanisms may be associated with increased metastasis under the influence of calcitriol.

However, in our previous studies using the human and mouse colon cancer model transplanted subcutaneously or orthotopically, we observed that both calcitriol analogs increased VDR level in colon tumor tissue, and when used with 5-fluorouracil, PRI-2191 decreased the number of lymph node metastases $(21,30)$. We also correlated these observations with the increased E-cadherin levels after calcitriol or PRI-2191 treatment (30). It seems that the use of strategies that can 'activate' VDR should be tested to sensitize 4T1 cells to calcitriol. It can lead to direct influence of calcitriol on cancer cells [inhibitory effect, as in 67NR, 168FARN (91), or our colon cancer models $(21,30)]$ and to predominance of direct tumor-suppressive effects over indirect, host related tumor-conducive ones.

Our results for the first time indicated that the treatment with calcitriol or its analogs may lead to the acceleration of metastatic process. There are published data proving that calcitriol or its analogs inhibit growth of breast cancer xenografts $(100,101)$ or transplantable mouse mammary gland cancer $(23,102)$. Moreover studies by Williams et al showed accelerated primary mammary gland tumor (MMTV-wt) growth upon vitamin D deficient diet (91). Rossdeutsher et al, using non-immunodeficient model of spontaneous mammary gland cancer MMTV-PyMT, showed that exogenous 25(OH)D delays neoplasia, tumor growth, and metastasis (103). On the other hand, Ooi et al proved in experimental bone metastasis model of human breast cancer cell xenotransplantation, that vitamin $\mathrm{D}$ deficiency promotes the growth of human breast cancer cells in the bones of nude mice (104). However, both cancer cell lines used in these studies were sensitive to vitamin D action $(103,104)$. The 4T1 cells, although expressing VDR, are not sensitive to calcitriol: cell proliferation in vitro and tumor growth in vivo was not affected upon treatment. Therefore, calcitriol or its analogs in the body milieu modified by 4T1 cells exerts its specific action on sensitive host cells and by such indirect way accelerate metastatic process.

In conclusion, we have shown that calcitriol and its analogs enhance the metastatic potential of 4T1 mouse mammary gland cancer inducing OPN secretion by host cells (macrophages, endothelial cells, or CAFs) in tumor tissue. Overexpression of OPN in tumor tissue prevailed over the decreased tumor TGF $\beta$ level and blood vessel normalization via tumor VEGF deprivation induced by calcitriol or its analogs. Furthermore, induced plasma TGF $\beta$ and $17 \beta$-estradiol levels can contribute to the facilitation of metastatic process via promoting metastatic niche formation (Fig. 13). Collectively these data indicate that caution should be taken with the use of vitamin D in breast cancer therapy. However, further studies are needed to show what characteristics of tumor cells modulating tumor microenvironment are responsible for the predominance of vitamin D prometastatic effects.

\section{Acknowledgements}

This study was supported by the National Science Center granted on the basis of the decision number DEC-2013/11/B/ NZ5/00162. This study was also supported by Wroclaw Center of Biotechnology within a program - The Leading National Research Center (KNOW) for years 2014-2018.

\section{References}

1. Cossetti RJD, Tyldesley SK, Speers CH, Zheng Y and Gelmon KA: Comparison of breast cancer recurrence and outcome patterns between patients treated from 1986 to 1992 and from 2004 to 2008. J Clin Oncol 33: 65-73, 2015.

2. Riemsma R, Forbes CA, Kessels A, Lykopoulos K, Amonkar MM, Rea DW and Kleijnen J: Systematic review of aromatase inhibitors in the first-line treatment for hormone sensitive advanced or metastatic breast cancer. Breast Cancer Res Treat 123: 9-24, 2010.

3. Dutta U and Pant K: Aromatase inhibitors: Past, present and future in breast cancer therapy. Med Oncol 25: 113-124, 2008.

4. Brown SA and Guise TA: Cancer treatment-related bone disease. Crit Rev Eukaryot Gene Expr 19: 47-60, 2009.

5. Datta M and Schwartz GG: Calcium and vitamin D supplementation and loss of bone mineral density in women undergoing breast cancer therapy. Crit Rev Oncol Hematol 88: 613-624, 2013.

6. Rizzoli R, Body JJ, Brandi ML, Cannata-Andia J, Chappard D, El Maghraoui A, Glüer CC, Kendler D, Napoli N, Papaioannou A, et al; International Osteoporosis Foundation Committee of Scientific Advisors Working Group on Cancer-Induced Bone Disease: Cancer-associated bone disease. Osteoporos Int 24: 2929-2953, 2013. 
7. Coleman R, Body JJ, Aapro M, Hadji P and Herrstedt J; ESMO Guidelines Working Group: Bone health in cancer patients: ESMO Clinical Practice Guidelines. Ann Oncol 25 (Suppl 3): iii124-iii137, 2014

8. Coleman RE, Rathbone E and Brown JE: Management of cancer treatment-induced bone loss. Nat Rev Rheumatol 9: 365-374, 2013.

9. Cepa M and Vaz C: Management of bone loss in postmenopausal breast cancer patients treated with aromatase inhibitors. Acta Reumatol Port 40: 323-330, 2015.

10. Hant FN and Bolster MB: Drugs that may harm bone: Mitigating the risk. Cleve Clin J Med 83: 281-288, 2016.

11. Brant J: Vitamin D in the prevention of aromatase inhibitorinduced musculoskeletal symptoms: Is it ready for practice? J Adv Pract Oncol 3: 245-248, 2012.

12. Jacobs ET, Kohler LN, Kunihiro AG and Jurutka PW: Vitamin D and colorectal, breast, and prostate cancers: A review of the epidemiological evidence. J Cancer 7: 232-240, 2016.

13. Feldman D, Krishnan AV, Swami S, Giovannucci E and Feldman BJ: The role of vitamin D in reducing cancer risk and progression. Nat Rev Cancer 14: 342-357, 2014.

14. Jacot W, Pouderoux S, Thezenas S, Chapelle A, Bleuse JP, Romieu G and Lamy PJ: Increased prevalence of vitamin D insufficiency in patients with breast cancer after neoadjuvant chemotherapy. Breast Cancer Res Treat 134: 709-717, 2012.

15. Singer O, Cigler T, Moore AB, Levine AB, Do HT and Mandl LA Hypovitaminosis D is a predictor of aromatase inhibitor musculoskeletal symptoms. Breast J 20: 174-179, 2014.

16. LaPorta $\mathrm{E}$ and Welsh J: Modeling vitamin $\mathrm{D}$ actions in triple negative/basal-like breast cancer. J Steroid Biochem Mol Biol 144A: 65-73, 2014.

17. Peppone LJ, Rickles AS, Janelsins MC, Insalaco MR and Skinner KA: The association between breast cancer prognostic indicators and serum 25-OH vitamin D levels. Ann Surg Oncol 19: 2590-2599, 2012.

18. Ness RA, Miller DD and Li W: The role of vitamin D in cancer prevention. Chin J Nat Med 13: 481-497, 2015.

19. Horst R, Prapong S, Reinhardt T, Koszewski N, Knutson J and Bishop C: Comparison of the relative effects of 1,24-dihydroxyvitamin $\mathrm{D}(2)[1,24-(\mathrm{OH})(2) \mathrm{D}(2)], 1,24$-dihydroxyvitamin $\mathrm{D}(3)$ $[1,24-(\mathrm{OH})(2) \mathrm{D}(3)]$, and 1,25-dihydroxy vitamin $\mathrm{D}(3)$ [1,25-(OH) (2)D(3)] on selected vitamin D-regulated events in the rat. Biochem Pharmacol 60: 701-708, 2000.

20. Wietrzyk J, Pełczyńska M, Madej J, Dzimira S, Kuśnierczyk H, Kutner A, Szelejewski W and Opolski A: Toxicity and antineoplastic effect of (24R)-1,24-dihydroxyvitamin D3 (PRI-2191). Steroids 69: 629-635, 2004

21. Milczarek M, Filip-Psurska B, Swietnicki W, Kutner A and Wietrzyk J: Vitamin D analogs combined with 5-fluorouracil in human HT-29 colon cancer treatment. Oncol Rep 32: 491-504, 2014.

22. Wietrzyk J, Chodyński M, Fitak H, Wojdat E, Kutner A and Opolski A: Antitumor properties of diastereomeric and geometric analogs of vitamin D3. Anticancer Drugs 18: 447-457, 2007.

23. Milczarek M, Chodyński M, Filip-Psurska B, Martowicz A, Krupa M, Krajewski K, Kutner A and Wietrzyk J: Synthesis and biological activity of diastereomeric and geometric analogs of calcipotriol, PRI-2202 and PRI-2205, against human HL-60 leukemia and MCF-7 breast cancer cells. Cancers (Basel) 5 $1355-1378,2013$.

24. Filip B, Milczarek M, Wietrzyk J, Chodyński M and Kutner A Antitumor properties of (5E,7E) analogs of vitamin D3. J Steroid Biochem Mol Biol 121: 399-402, 2010.

25. Hisatake J, Kubota T, Hisatake Y, Uskokovic M, Tomoyasu S and Koeffler HP: 5,6-trans-16-ene-vitamin D3: A new class of potent inhibitors of proliferation of prostate, breast, and myeloid leukemic cells. Cancer Res 59: 4023-4029, 1999.

26. Opolski A, Wietrzyk J, Siwinska A, Marcinkowska E, Chrobak A, Radzikowski C and Kutner A: Biological activity in vitro of side-chain modified analogues of calcitriol. Curr Pharm Des 6: $755-765,2000$

27. Wietrzyk J, Nevozhay D, Filip B, Milczarek M and Kutner A The antitumor effect of lowered doses of cytostatics combined with new analogs of vitamin D in mice. Anticancer Res 27A: 3387-3398, 2007

28. Wietrzyk J, Milczarek M and Kutner A: The effect of combined treatment on head and neck human cancer cell lines with novel analogs of calcitriol and cytostatics. Oncol Res 16: 517-525, 2007.
29. Wietrzyk J, Nevozhay D, Milczarek M, Filip B and Kutner A Toxicity and antitumor activity of the vitamin D analogs PRI-1906 and PRI-1907 in combined treatment with cyclophosphamide in a mouse mammary cancer model. Cancer Chemother Pharmacol 62: 787-797, 2008

30. Milczarek M, Psurski M, Kutner A and Wietrzyk J: Vitamin D analogs enhance the anticancer activity of 5-fluorouracil in an in vivo mouse colon cancer model. BMC Cancer 13: 294, 2013.

31. Maj E, Filip-Psurska B, Świtalska M, Kutner A and Wietrzyk J: Vitamin D analogs potentiate the antitumor effect of imatinib mesylate in a human A549 lung tumor model. Int J Mol Sci 16: 27191-27207, 2015

32. Blazejczyk A, Papiernik D, Porshneva K, Sadowska J and Wietrzyk J: Endothelium and cancer metastasis: Perspectives for antimetastatic therapy. Pharmacol Rep 67: 711-718, 2015.

33. Chodyński M, Wietrzyk J, Marcinkowska E, Opolski A, Szelejewski W and Kutner A: Synthesis and antiproliferative activity of side-chain unsaturated and homologated analogs of 1,25-dihydroxyvitamin D(2). (24E)-(1S)-24-Dehydro-24ahomo-1,25-dihydroxyergocalciferol and congeners. Steroids 67: 789-798, 2002.

34. DuPré SA, Redelman D and Hunter KW Jr: The mouse mammary carcinoma 4T1: Characterization of the cellular landscape of primary tumours and metastatic tumour foci. Int J Exp Pathol 88 : 351-360, 2007

35. Nevozhay D: Cheburator software for automatically calculating drug inhibitory concentrations from in vitro screening assays. PLoS One 9: e106186, 2014.

36. Wenzel J, Zeisig R and Fichtner I: Inhibition of metastasis in a murine 4T1 breast cancer model by liposomes preventing tumor cell-platelet interactions. Clin Exp Metastasis 27: 25-34, 2010.

37. DuPre' SA and Hunter KW Jr: Murine mammary carcinoma 4T1 induces a leukemoid reaction with splenomegaly: Association with tumor-derived growth factors. Exp Mol Pathol 82: 12-24, 2007.

38. Banka CL, Lund CV, Nguyen MTN, Pakchoian AJ, Mueller BM and Eliceiri BP: Estrogen induces lung metastasis through a host compartment-specific response. Cancer Res 66: 3667-3672, 2006.

39. MacRitchie AN, Jun SS, Chen Z, German Z, Yuhanna IS Sherman TS and Shaul PW: Estrogen upregulates endothelial nitric oxide synthase gene expression in fetal pulmonary artery endothelium. Circ Res 81: 355-362, 1997.

40. Yang X, Belosay A, Du M, Fan TM, Turner RT, Iwaniec UT and Helferich WG: Estradiol increases ER-negative breast cancer metastasis in an experimental model. Clin Exp Metastasis 30: 711-721, 2013.

41. Garcia CM de S, de Araújo MR, Lopes MTP, Ferreira MAND and Cassali GD: Morphological and immunophenotipical characterization of murine mammary carcinoma $4 \mathrm{t} 1$. Braz J Vet Pathol 7: 158-165, 2014

42. Mi Z, Guo H, Wai PY, Gao C, Wei J and Kuo PC: Differential osteopontin expression in phenotypically distinct subclones of murine breast cancer cells mediates metastatic behavior. J Biol Chem 279: 46659-46667, 2004.

43. Sangaletti S, Tripodo C, Sandri S, Torselli I, Vitali C, Ratti C, Botti L, Burocchi A, Porcasi R, Tomirotti A, et al: Osteopontin shapes immunosuppression in the metastatic niche. Cancer Res 74: 4706-4719, 2014.

44. Pang H, Lu H, Song H, Meng Q, Zhao Y, Liu N, Lan F, Liu Y, Yan S, Dong X, et al: Prognostic values of osteopontin-c, E-cadherin and $\beta$-catenin in breast cancer. Cancer Epidemiol 37: 985-992, 2013

45. Chang P-L, Harkins L, Hsieh Y-H, Hicks P, Sappayatosok K, Yodsanga S, Swasdison S, Chambers AF, Elmets CA and Ho KJ: Osteopontin expression in normal skin and non-melanoma skin tumors. J Histochem Cytochem 56: 57-66, 2008.

46. Yin M, Soikkeli J, Jahkola T, Virolainen S, Saksela O and Hölttä E: Osteopontin promotes the invasive growth of melanoma cells by activating integrin $\alpha v \beta 3$ and down-regulating tetraspanin CD9. Am J Pathol 184: 842-858, 2014.

47. Sulpice L, Rayar M, Desille M, Turlin B, Fautrel A, Boucher E, Llamas-Gutierrez F, Meunier B, Boudjema K, Clément B, et al: Molecular profiling of stroma identifies osteopontin as an independent predictor of poor prognosis in intrahepatic cholangiocarcinoma. Hepatology 58: 1992-2000, 2013.

48. Pang H, Cai L, Yang Y, Chen X, Sui G and Zhao C: Knockdown of osteopontin chemosensitizes MDA-MB-231 cells to cyclophosphamide by enhancing apoptosis through activating p38 MAPK pathway. Cancer Biother Radiopharm 26: 165-173, 2011. 
49. Denhardt DT, Noda M, O'Regan AW, Pavlin D and Berman JS: Osteopontin as a means to cope with environmental insults: Regulation of inflammation, tissue remodeling, and cell survival. J Clin Invest 107: 1055-1061, 2001.

50. Kon S, Nakayama Y, Matsumoto N, Ito K, Kanayama M, Kimura C, Kouro H, Ashitomi D, Matsuda T and Uede T: A novel cryptic binding motif, LRSKSRSFQVSDEQY, in the C-terminal fragment of MMP-3/7-cleaved osteopontin as a novel ligand for $\alpha 9 \beta 1$ integrin is involved in the anti-type II collagen antibodyinduced arthritis. PLoS One 9: e116210, 2014.

51. Barry ST, Ludbrook SB, Murrison E and Horgan CM: A regulated interaction between alpha5beta1 integrin and osteopontin. Biochem Biophys Res Commun 267: 764-769, 2000.

52. Helluin O, Chan C, Vilaire G, Mousa S, DeGrado WF and Bennett JS: The activation state of alphavbeta 3 regulates platelet and lymphocyte adhesion to intact and thrombin-cleaved osteopontin. J Biol Chem 275: 18337-18343, 2000.

53. Kale S, Raja R, Thorat D, Soundararajan G, Patil TV and Kundu GC: Osteopontin signaling upregulates cyclooxygenase-2 expression in tumor-associated macrophages leading to enhanced angiogenesis and melanoma growth via $\alpha 9 \beta 1$ integrin. Oncogene 33: 2295-2306, 2014.

54. Raja R, Kale S, Thorat D, Soundararajan G, Lohite K, Mane A, Karnik S and Kundu GC: Hypoxia-driven osteopontin contributes to breast tumor growth through modulation of HIF1 $\alpha$-mediated VEGF-dependent angiogenesis. Oncogene 33: 2053-2064, 2014.

55. Noda M, Vogel RL, Craig AM, Prahl J, DeLuca HF and Denhardt DT: Identification of a DNA sequence responsible for binding of the 1,25-dihydroxyvitamin D3 receptor and 1,25-dihydroxyvitamin D3 enhancement of mouse secreted phosphoprotein 1 (SPP-1 or osteopontin) gene expression. Proc Natl Acad Sci USA 87: 9995-9999, 1990.

56. Xu H, McCann M, Zhang Z, Posner GH, Bingham V, El-Tanani M and Campbell FC: Vitamin D receptor modulates the neoplastic phenotype through antagonistic growth regulatory signals. Mol Carcinog 48: 758-772, 2009.

57. Lau WL, Leaf EM, Hu MC, Takeno MM, Kuro-o M, Moe OW and Giachelli CM: Vitamin D receptor agonists increase klotho and osteopontin while decreasing aortic calcification in mice with chronic kidney disease fed a high phosphate diet. Kidney Int 82: 1261-1270, 2012.

58. Hu B, Zhou H, Gao H, Liu Y, Yan T, Zou L and Chen L: IFN- $\gamma$ inhibits osteopontin expression in human decidual stromal cells and can be attenuated by $1 \alpha, 25$-dihydroxyvitamin D3. Am J Reprod Immunol 68: 353-361, 2012.

59. Chang PL, Ridall AL and Prince CW: Calcitriol regulation of osteopontin expression in mouse epidermal cells. Endocrinology 135: 863-869, 1994.

60. Chang PL and Prince CW: $1 \alpha, 25$-dihydroxyvitamin D3 stimulates synthesis and secretion of nonphosphorylated osteopontin (secreted phosphoprotein 1) in mouse JB6 epidermal cells. Cancer Res 51: 2144-2150, 1991.

61. Blomberg Jensen M, Jørgensen A, Nielsen JE, Steinmeyer A, Leffers H, Juul A and Rajpert-De Meyts E: Vitamin D metabolism and effects on pluripotency genes and cell differentiation in testicular germ cell tumors in vitro and in vivo. Neoplasia 14 952-963, 2012.

62. Chakraborty G, Jain S and Kundu GC: Osteopontin promotes vascular endothelial growth factor-dependent breast tumor growth and angiogenesis via autocrine and paracrine mechanisms. Cancer Res 68: 152-161, 2008.

63. Das S, Samant RS and Shevde LA: Nonclassical activation of Hedgehog signaling enhances multidrug resistance and makes cancer cells refractory to Smoothened-targeting Hedgehog inhibition. J Biol Chem 288: 11824-11833, 2013.

64. Shevde LA and Samant RS: Role of osteopontin in the pathophysiology of cancer. Matrix Biol 37: 131-141, 2014.

65. Johnstone CN, Smith YE, Cao Y, Burrows AD, Cross RS Ling X, Redvers RP, Doherty JP, Eckhardt BL, Natoli AL, et al: Functional and molecular characterisation of EO771.LMB tumours, a new C57BL/6-mouse-derived model of spontaneously metastatic mammary cancer. Dis Model Mech 8: 237-251, 2015.

66. Yu Y, Xiao C-H, Tan L-D, Wang Q-S, Li X-Q and Feng Y-M: Cancer-associated fibroblasts induce epithelial-mesenchymal transition of breast cancer cells through paracrine TGF- $\beta$ signalling. Br J Cancer 110: 724-732, 2014.

67. Inai T, Mancuso M, Hashizume H, Baffert F, Haskell A, Baluk P, Hu-Lowe DD, Shalinsky DR, Thurston G, Yancopoulos GD, et al Inhibition of vascular endothelial grow th factor (VEGF) signaling in cancer causes loss of endothelial fenestrations, regression of tumor vessels, and appearance of basement membrane ghosts. Am J Pathol 165: 35-52, 2004
68. Maj E, Papiernik D and Wietrzyk J: Antiangiogenic cancer treatment: The great discovery and greater complexity (Review). Int J Oncol 49: 1773-1784, 2016.

69. Molin DGM, van den Akker NM and Post MJ: Affirmative action of osteopontin on endothelial progenitors. Arterioscler Thromb Vasc Biol 28: 2099-2100, 2008.

70. Leen LLS, Filipe C, Billon A, Garmy-Susini B, Jalvy S, Robbesyn F, Daret D, Allières C, Rittling SR, Werner N, et al: Estrogen-stimulated endothelial repair requires osteopontin. Arterioscler Thromb Vasc Biol 28: 2131-2136, 2008.

71. Pepper MS: Transforming growth factor-beta: Vasculogenesis, angiogenesis, and vessel wall integrity. Cytokine Growth Factor Rev 8: 21-43, 1997.

72. Costanza B, Umelo IA, Bellier J, Castronovo V and Turtoi A: Stromal modulators of TGF- $\beta$ in cancer. J Clin Med 6: 7, 2017.

73. Nakagawa T, Li JH, Garcia G, Mu W, Piek E, Böttinger EP, Chen Y, Zhu HJ, Kang DH, Schreiner GF, et al: TGF- $\beta$ induces proangiogenic and antiangiogenic factors via parallel but distinct Smad pathways. Kidney Int 66: 605-613, 2004.

74. Orlova VV, Liu Z, Goumans M-J and ten Dijke P: Controlling angiogenesis by two unique TGF- $\beta$ type I receptor signaling pathways. Histol Histopathol 26: 1219-1230, 2011.

75. Goumans M-J, Valdimarsdottir G, Itoh S, Rosendahl A, Sideras P and ten Dijke P: Balancing the activation state of the endothelium via two distinct TGF-beta type I receptors. EMBO J 21: 1743-1753, 2002.

76. Khan Z and Marshall JF: The role of integrins in TGF $\beta$ activation in the tumour stroma. Cell Tissue Res 365: 657-673, 2016

77. Takai K, Le A, Weaver VM and Werb Z: Targeting the cancerassociated fibroblasts as a treatment in triple-negative breast cancer. Oncotarget 7: 82889-82901, 2016.

78. Sharon Y, Raz Y, Cohen N, Ben-Shmuel A, Schwartz H, Geiger T and Erez N: Tumor-derived osteopontin reprograms normal mammary fibroblasts to promote inflammation and tumor growth in breast cancer. Cancer Res 75: 963-973, 2015.

79. Weber CE, Kothari AN, Wai PY, Li NY, Driver J, Zapf MA, Franzen CA, Gupta GN, Osipo C, Zlobin A, et al: Osteopontin mediates an MZF1-TGF- $\beta 1$-dependent transformation of mesenchymal stem cells into cancer-associated fibroblasts in breast cancer. Oncogene 34: 4821-4833, 2015.

80. Koli K and Keski-Oja J: 1,25-Dihydroxyvitamin D3 enhances the expression of transforming growth factor beta 1 and its latent form binding protein in cultured breast carcinoma cells. Cancer Res 55: 1540-1546, 1995.

81. Shany S, Sigal-Batikoff I and Lamprecht S: Vitamin D and myofibroblasts in fibrosis and cancer: At cross-purposes with TGF- $\beta /$ SMAD signaling. Anticancer Res 36: 6225-6234, 2016.

82. Tao Q, Wang B, Zheng Y, Jiang X, Pan Z and Ren J: Vitamin D prevents the intestinal fibrosis via induction of vitamin D receptor and inhibition of transforming growth factor-beta1/ Smad3 pathway. Dig Dis Sci 60: 868-875, 2015.

83. Ivanović V,Demajo M,KrtolicaK,KrajnovićM,Konstantinović M, Baltić V, Prtenjak G, Stojiljković B, Breberina M, NeskovićKonstantinović Z, et al: Elevated plasma TGF- $\beta 1$ levels correlate with decreased survival of metastatic breast cancer patients. Clin Chim Acta 371: 191-193, 2006.

84. Moo-Young TA, Larson JW, Belt BA, Tan MC, Hawkins WG, Eberlein TJ, Goedegebuure PS and Linehan DC: Tumor-derived TGF-beta mediates conversion of $\mathrm{CD}^{+}{ }^{+} \mathrm{Foxp} 3^{+}$regulatory $\mathrm{T}$ cells in a murine model of pancreas cancer. J Immunother 32: 12-21, 2009.

85. Gong D, Shi W, Yi SJ, Chen H, Groffen J and Heisterkamp N: TGF $\beta$ signaling plays a critical role in promoting alternative macrophage activation. BMC Immunol 13: 31, 2012.

86. Fridlender ZG, Sun J, Kim S, Kapoor V, Cheng G, Ling L, Worthen GS and Albelda SM: Polarization of tumor-associated neutrophil phenotype by TGF-beta: 'N1' versus 'N2' TAN. Cancer Cell 16: 183-194, 2009.

87. Wculek SK and Malanchi I: Neutrophils support lung colonization of metastasis-initiating breast cancer cells. Nature 528: 413-417, 2015.

88. Cho HJ, Jung JI, Lim DY, Kwon GT, Her S, Park JH and Park JHY: Bone marrow-derived, alternatively activated macrophages enhance solid tumor growth and lung metastasis of mammary carcinoma cells in a Balb/C mouse orthotopic model. Breast Cancer Res 14: R81, 2012.

89. Adams LS and Teegarden D: 1,25-dihydroxycholecalciferol inhibits apoptosis in C3H10T1/2 murine fibroblast cells through activation of nuclear factor kappaB. J Nutr 134: 2948-2952, 2004. 
90. Cohen-Lahav M, Shany S, Tobvin D, Chaimovitz C and Douvdevani A: Vitamin D decreases NFkappaB activity by increasing IkappaBalpha levels. Nephrol Dial Transplant 21: 889-897, 2006

91. Williams JD, Aggarwal A, Swami S, Krishnan AV, Ji L, Albertelli MA and Feldman BJ: Tumor autonomous effects of Vitamin D deficiency promote breast cancer metastasis. Endocrinology 157: 1341-1347, 2016.

92. Aslakson CJ and Miller FR: Selective events in the metastatic process defined by analysis of the sequential dissemination of subpopulations of a mouse mammary tumor. Cancer Res 52: 1399-1405, 1992.

93. Simões RV, Serganova IS, Kruchevsky N, Leftin A, Shestov AA, Thaler HT, Sukenick G, Locasale JW, Blasberg RG, Koutcher JA, et al: Metabolic plasticity of metastatic breast cancer cells: Adaptation to changes in the microenvironment. Neoplasia 17 671-684, 2015

94. Meyer MB, Benkusky NA, Kaufmann M, Lee SM, Onal M, Jones G and Pike JW: A Kidney-specific genetic control module in mice governs endocrine regulation of the cytochrome P450 gene Cyp27b1 essential for vitamin D 3 activation. J Biol Chem: 2017 Aug 14, 2017 (Epub ahead of print). doi: 10.1074/jbc. M117.806901.

95. Anderson PH: Vitamin D activity and metabolism in bone. Curr Osteoporos Rep 15: 443-449, 2017.

96. Marik R, Fackler M, Gabrielson E, Zeiger MA, Sukumar S, Stearns V and Umbricht CB: DNA methylation-related vitamin D receptor insensitivity in breast cancer. Cancer Biol Ther 10 44-53, 2010.

97. Banwell CM, O'Neill LP, Uskokovic MR and Campbell MJ: Targeting $1 \alpha, 25$-dihydroxyvitamin D3 antiproliferative insensitivity in breast cancer cells by co-treatment with histone deacetylation inhibitors. J Steroid Biochem Mol Biol 89-90: $245-249,2004$
98. Khanim FL, Gommersall LM, Wood VHJ, Smith KL, Montalvo L, O'Neill LP, Xu Y, Peehl DM, Stewart PM, Turner BM, et al: Altered SMRT levels disrupt vitamin D3 receptor signalling in prostate cancer cells. Oncogene 23: 6712-6725, 2004

99.Zhi H-Y, Hou S-W, Li R-S, Basir Z, Xiang Q, Szabo A and Chen G: PTPH1 cooperates with vitamin D receptor to stimulate breast cancer growth through their mutual stabilization. Oncogene 30: 1706-1715, 2011.

100. Krishnan AV, Swami S and Feldman D: Equivalent anticancer activities of dietary vitamin D and calcitriol in an animal model of breast cancer: Importance of mammary CYP27B1 for treatment and prevention. J Steroid Biochem Mol Biol 136: 289-295, 2013.

101. Swami S, Krishnan AV, Wang JY, Jensen K, Horst R, Albertelli MA and Feldman D: Dietary vitamin D3 and 1,25-dihydroxyvitamin D3 (calcitriol) exhibit equivalent anticancer activity in mouse xenograft models of breast and prostate cancer. Endocrinology 153: 2576-2587, 2012.

102. Jeong Y, Swami S, Krishnan AV, Williams JD, Martin S, Horst RL, Albertelli MA, Feldman BJ, Feldman D and Diehn M: Inhibition of mouse breast tumor-initiating cells by calcitriol and dietary vitamin D. Mol Cancer Ther 14: 1951-1961, 2015.

103. Rossdeutscher L, Li J, Luco A-L, Fadhil I, Ochietti B, Camirand A, Huang DC, Reinhardt TA, Muller W and Kremer R: Chemoprevention activity of 25-hydroxyvitamin D in the MMTV-PyMT mouse model of breast cancer. Cancer Prev Res (Phila) 8: 120-128, 2015.

104. Ooi LL, Zhou H, Kalak R, Zheng Y, Conigrave AD, Seibel MJ and Dunstan CR: Vitamin D deficiency promotes human breast cancer growth in a murine model of bone metastasis. Cancer Res 70: 1835-1844, 2010.

(1) (9) This work is licensed under a Creative Commons Attribution-NonCommercial-NoDerivatives 4.0 International (CC BY-NC-ND 4.0) License. 